UCRL-ID-127714

\title{
DAUPHIN \\ Containment Data Report
}

\author{
T. Stubbs \\ R. Heinle
}

June, 1997

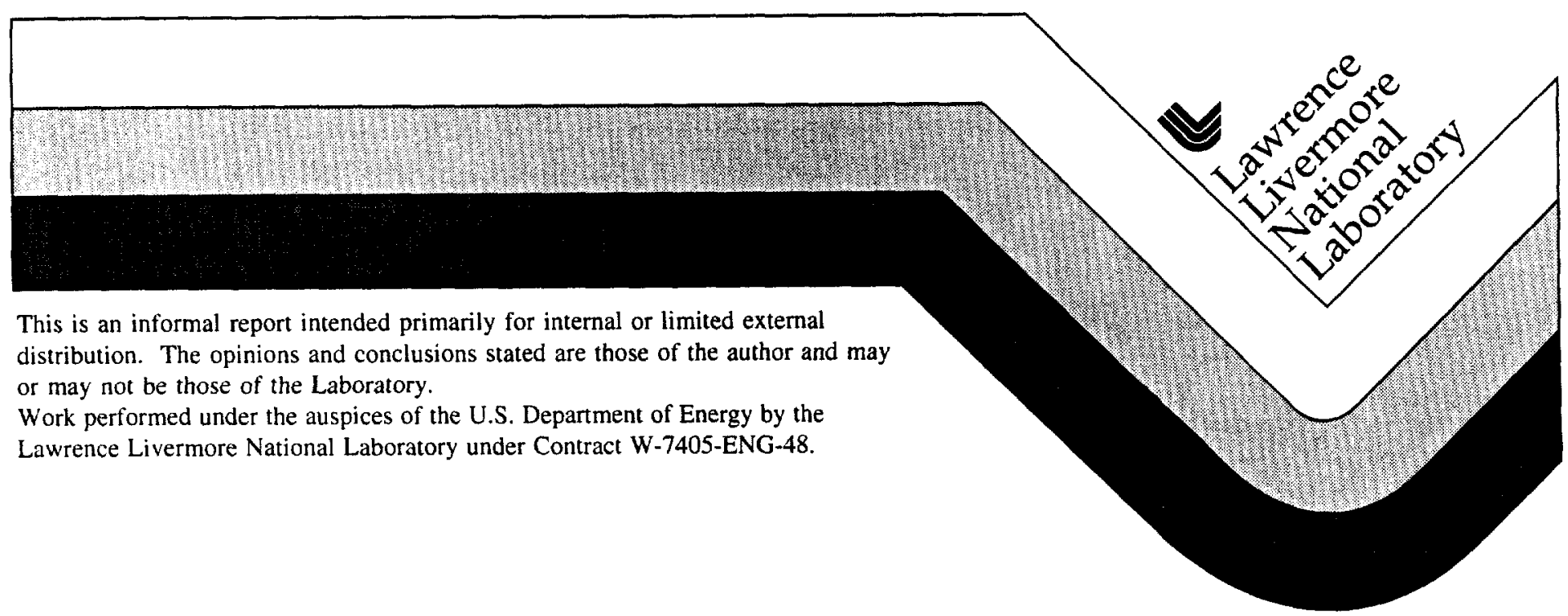




\section{DISCLAIMER}

This document was prepared as an account of work sponsored by an agency of the United States Government. Neither the United States Government nor the University of California nor any of their employees, makes any warranty, express or implied, or assumes any legal liability or responsibility for the accuracy, completeness, or usefulness of any information, apparatus, product, or process disclosed, or represents that its use would not infringe privately owned rights. Reference herein to any specific commercial products, process, or service by trade name, trademark, manufacturer, or otherwise, does not necessarily constitute or imply its endorsement, recommendation, or favoring by the United States Government or the University of California. The views and opinions of authors expressed herein do not necessarily state or reflect those of the United States Government or the University of California, and shall not be used for advertising or product endorsement purposes.

This report has been reproduced directly from the best available copy.

Available to DOE and DOE contractors from the Office of Scientific and Technical Information P.O. Box 62, Oak Ridge, TN 37831

Prices available from (615) 576-8401, FTS 626-8401

Available to the public from the National Technical Information Service

U.S. Department of Commerce 5285 Port Royal Road Springfield, VA 22161 
DAUPHIN Instrumentation SUmmanx

\begin{tabular}{|c|c|c|c|}
\hline Instrumentation & $\begin{array}{l}\text { Fielded on } \\
\text { this Event }\end{array}$ & $\begin{array}{c}\text { Data } \\
\text { Return }\end{array}$ & $\begin{array}{l}\text { Present in } \\
\text { this Report }\end{array}$ \\
\hline Plug Emplacement & yes & yes & yes $(a)$ \\
\hline Radiation & yes & yes & yes \\
\hline Pressure & & & \\
\hline Stemming & yes & yes & yes \\
\hline Challenge & no & - & - \\
\hline Cavity & no & - & - \\
\hline Atmospheric & no & - & - \\
\hline Motion & & & \\
\hline Free Field & no & - & $\cdot$ \\
\hline Surtace & yes & yes & yes \\
\hline Plug & yes & yes & yes \\
\hline Stemming & yes & yes & yes \\
\hline Surface Casing & no & - & - \\
\hline Emplacement Pipe & yes & yes & yes \\
\hline Hydroyield & no & - & - \\
\hline Collapse $^{(b)}$ & yes & yes & yes \\
\hline Stress & no & - & - \\
\hline Strain $(c)$ & yes & yes & yes \\
\hline Other Measurements & no & - & - \\
\hline
\end{tabular}

(a) Description only.

(b) EXCOR or CLIPER and D-cable in emplacement hole.

(c) Strain load on emplacement pipe.

\section{Event Personnel}

Containment Physics
B. Hudson
C. Olsen
J. Kalinowski
T. Stubbs
LLNL
LLNL
EG\&G/AVO
EG\&G/AVO

Instrumentation

$\begin{array}{ll}\text { L. Starm } & \text { LLNL } \\ \text { F. Sierra } & \text { EG\&G/AVO } \\ \text { L. Davies } & \text { EG\&G/NVO } \\ \text { R. Sievert } & \text { EG\&G/NVO }\end{array}$


Contents

1. Event Description

1.1 Site

1.2 Emplacement

1.3 Instrumentation

2. Stemming Performance

2.1 Radiation and Pressure

2.2 Motion .

3. Collapse phenomena

3.1 Motion .

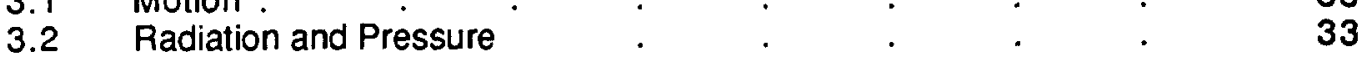

References

50 


\subsection{Instrumentation}

Figure 1.4 is a schematic layout of the instrumentation designed to monitor the containment performance of the DAUPHIN event.

Twelve stations were fielded in the stemming to monitor pressure and radiation. The stemming region within $5 \mathrm{~m}$ beneath each of the three lower rigid plugs contained pressure and radiation stations as well as the stemming about $5 \mathrm{~m}$ above the two bottom plugs. Additionally, four elevations in the coarse stemming above and below the two fines layers between the diagnostics canister and the bottom plug were monitored for pressure and radiation. The coarse material immediately below the fines supporting the bottom rigid plug (the formation coupling plug) was instrumented with a standard system and an experimental digital station. Midway between plugs 2 and 3 was the location of an additional pressure and radiation station.

Standard LLNL vertical motion canisters, containing variable reluctance velocity and acceleration transducers, were emplaced in all four of the rigid stemming plugs, the ground surface, $15.24 \mathrm{~m}$ from SGZ, and in the recording trailer. Additionally, one motion station was fielded in the coarse stemming about $20 \mathrm{~m}$ below the bottom rigid plug and above the second fines layer.

Data from each of the above instruments were transmitted to the recording trailer by an analog system and recorded on magnetic tape.

One CLIPER sensor and one "D-cable" system were fielded to monitor the stemming emplacement and recorded post-shot to sense collapse.

Yield measurements were not attempted as part of the containment measurements.

A history of the fielding operations of the instrumentation is outlined in reference 3 . Further details of the instrumentation are given in reference 4. 
1. Event Description

1.1 Site

The DAUPHIN event was detonated in hole U9cq of the Nevada Test Site as indicated in figure 1.1. The DAUPHIN device had a depth-of-burial (DOB) of $319 \mathrm{~m}$ in the Tunnel Beds Tuffs of area 9, about $200 \mathrm{~m}$ above the Paleozoic formation and about $300 \mathrm{~m}$ above the standing water level, as shown in the geologic cross-sections of figure $1.2^{(1)}$. Stemming of the $2.44 \mathrm{~m}$ diameter emplacement hole followed the plan shown in figure 1.3. A log of the stemming operations was maintained by Holmes \& Narver(2).

Detonation time was 08:50 PST on November 14, 1980, and collapse progressed to the surface at about 27.5 minutes after the detonation resulting in an asymetric crater having a mean radius of $71.9 \mathrm{~m}$ and a maximum depth of $13.0 \mathrm{~m}$.

No radiation arrivals were detected above ground and the DAUPHIN containment was considered successful.

\subsection{Emplacement}

There were four stemming plugs above the DAUPHIN event, each composed of rigid twopart- epoxy (TPE). The bottom plug was $7.9 \mathrm{~m}$ thick and the first intermediate plug was $3.7 \mathrm{~m}$ thick. A drag ring was mounted to the emplacement pipe at the position of the bottom rigid plug and the emplacement pipe in the regions of the remaining three plugs was coated with hydroseal to allow free motion of the pipe through these plugs. The second intermediate plug was $4.6 \mathrm{~m}$ thick and extended $2 \mathrm{~m}$ into the bottom of the surface casing. Thickness of the top TPE plug (near the top of the surface casing) was $3.5 \mathrm{~m}$. This was overlain with a $2.1 \mathrm{~m}$ thick layer of soft "coal-tar epoxy" to act as a gas seal. The top plug was overlain with $0.3 \mathrm{~m}$ of Overton sand, leaving the top $3.7 \mathrm{~m}$ of the hole unfilled. Stemming between the plugs below the surface casing consisted of layers of fines and coarse gravel. Three D-cable sensors, two on the emplacement pipe and one on the instrumentation pendant were fielded exclusively to monitor the emplacement procedures and a new LSI computer-based system successfully correlated the stemming data. The emplacement pipe was grouted to the surface. See figure 1.3 . 


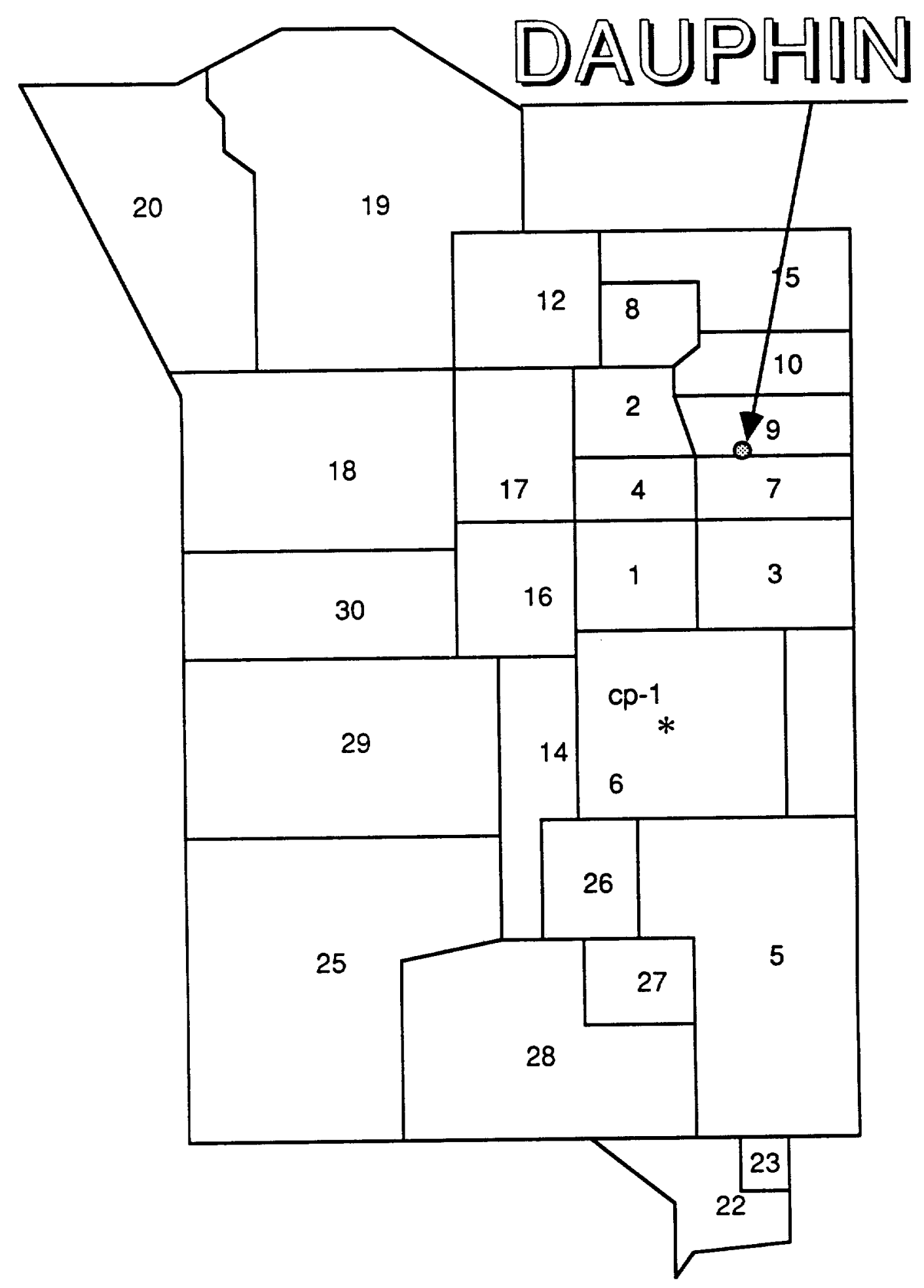

Figure 1.1 Map of the Nevada Test Site indicating the location of hole U9cq. 


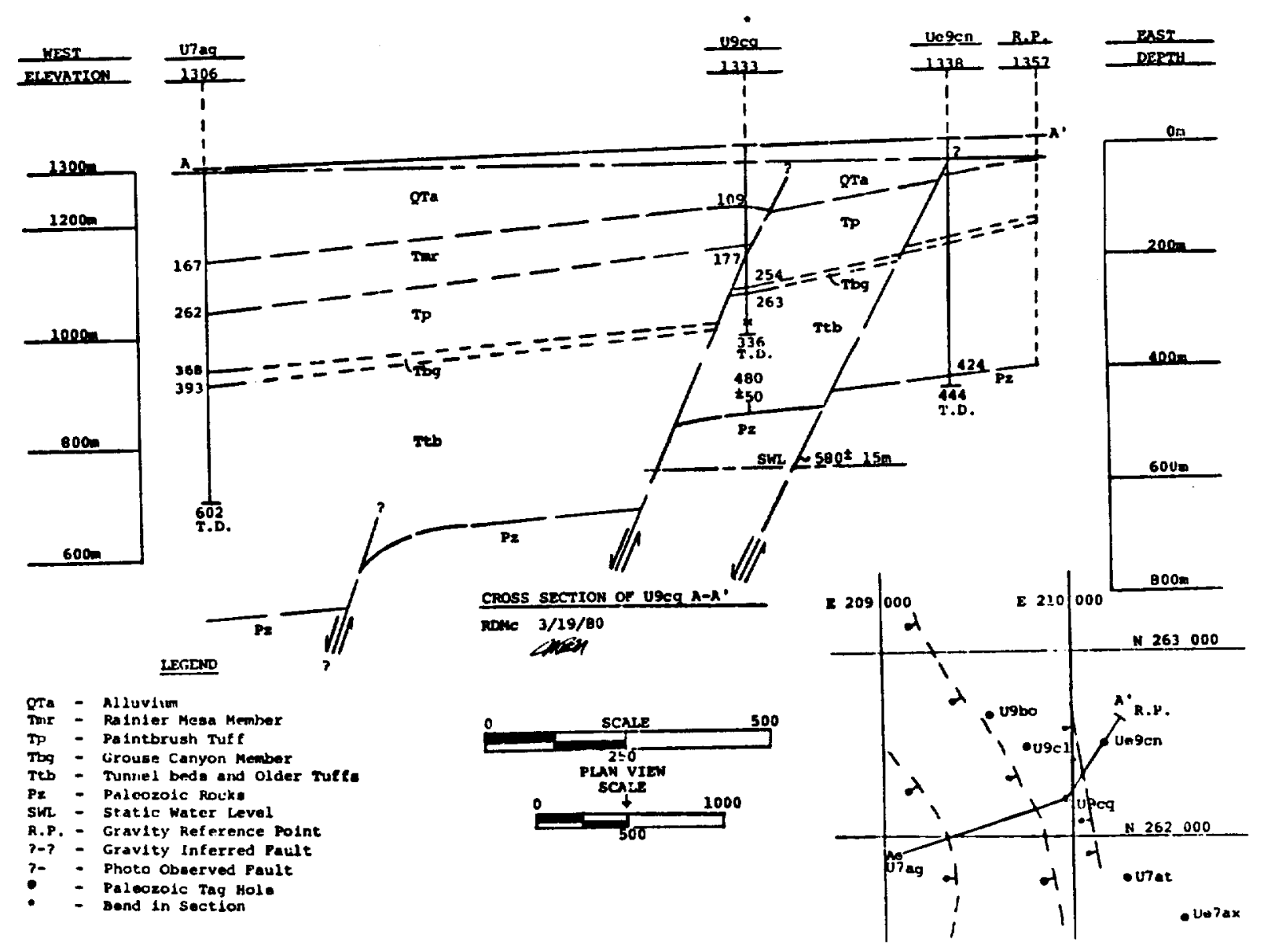

Figure 1.2 Northeast-Southwest geologic cross section through hole U9cq. 


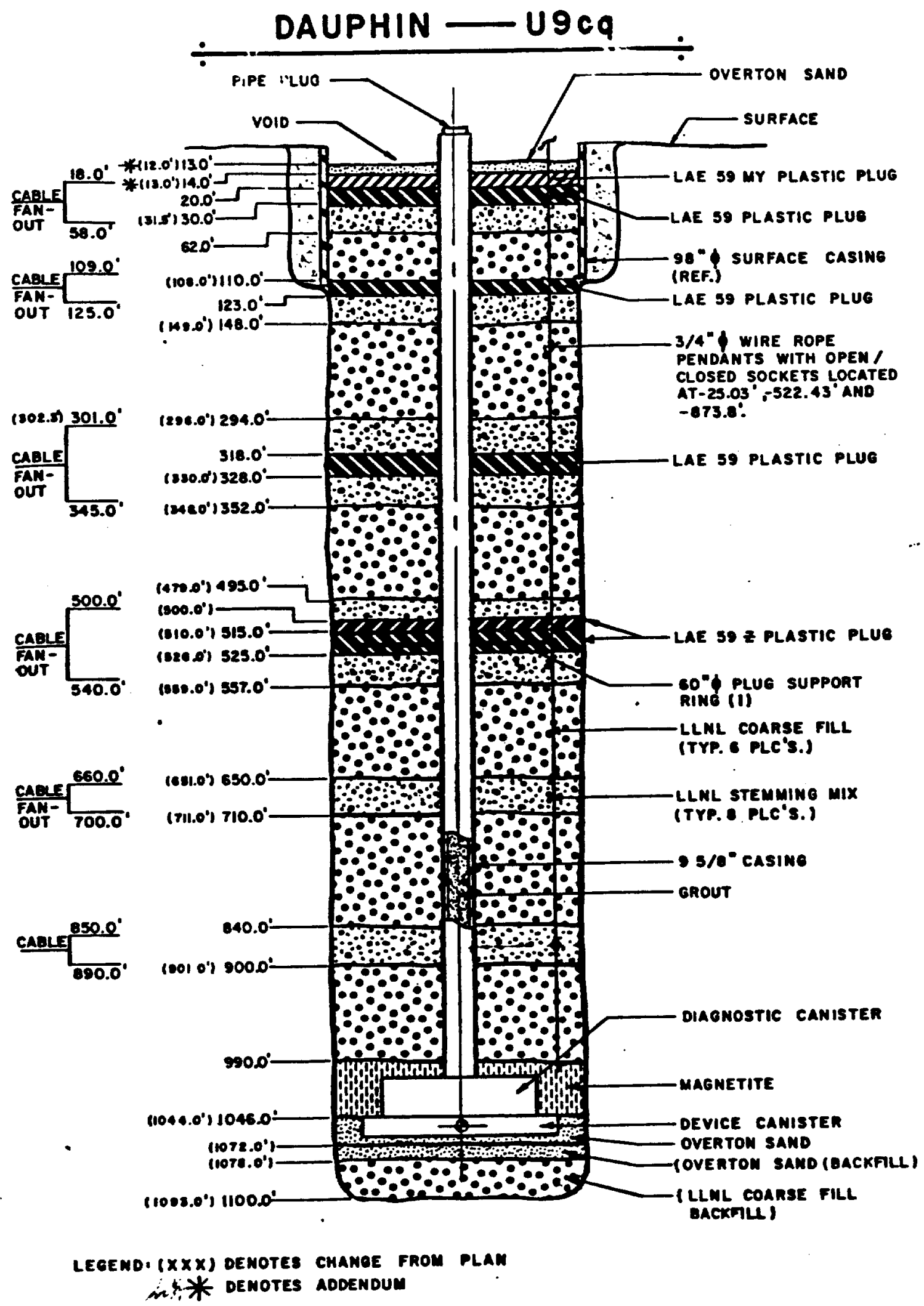

Figure 1.3 As-built stemming plan for the event DAUPHIN in Hole U9cq. 


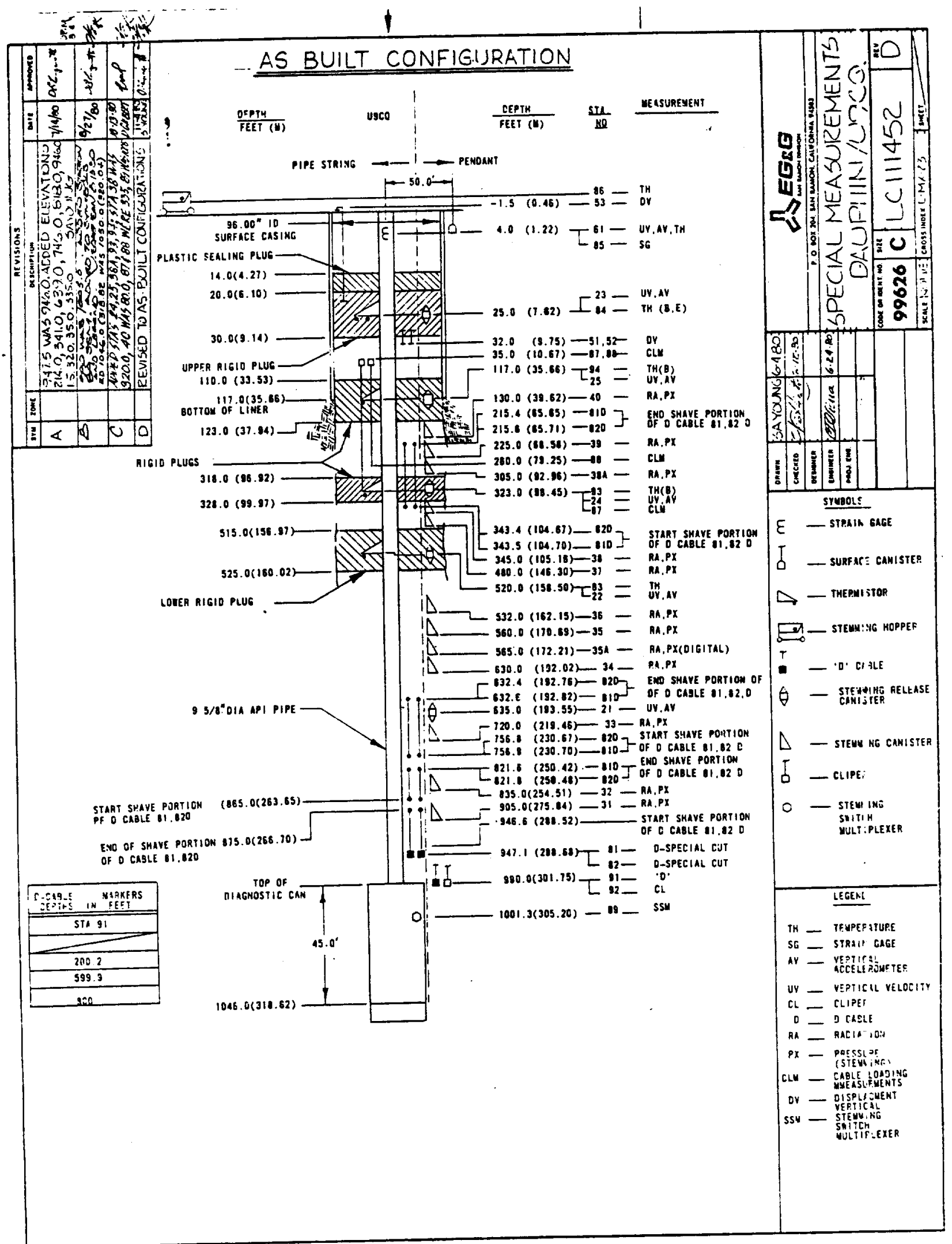

Figure 1.4 As-built containment instrumentation plan for the emplacement hole (U9cq) on the DAUPHIN event. 


\section{Stemmino Performance}

\subsection{Radiation and Pressure}

Pressure and radiation stations were fielded on the DAUPHIN at eleven locations as indicated in figure 1.5. A twelfth location was monitored with a new digital system, fielded for evaluation. In the final engineering report $(3)$ it is claimed that the data produced by this station are of high quality. They are, however, not available for this report. The pressure and radiation wave forms from about $50 \mathrm{~s}$ before detonation until $1800 \mathrm{~s}$ after, recorded at all stations, are shown in figures 2.1-2.11.

The pressure signal from station 31, below the deepest fines layer, (figure 2.1) was interrupted at or shortly after detonation. The radiation monitor at station 31 indicated a first radiation arrival at about $95 \mathrm{~s}$ reaching the system limit at about $145 \mathrm{~s}$ and lost prior to $200 \mathrm{~s}$. At station 32, above the deepest fines layer, (figure 2.2) the pressure jumps by about 24 psi at zero time and decays to about 4 psi above ambient at collapse time (about $1650 \mathrm{~s}$ ). A radiation arrival at station 32 is seen at about 210 s having the same wave form behavior as station 31 . No radiation arrival was seen at any other station above station 32 at any time.

Station 40 survived collapse (at about $1650 \mathrm{~s}$ ) and figure 2.11 shows the first $1800 \mathrm{~s}$ of pressure and radiation history. No radiation was detected at this station and the pressure history at collapse is characteristic of a stemming fall in a competent, porous medium.

Pressure histories across the coarse stemming between the two bottom fines layers (stations 32 and 33, figures 2.2 and 2.3) have nearly the same wave form but different magnitudes. Figure 2.12 shows the pressure difference between these two stations. All information from station 34 was lost at zero time. The difference in pressure between station 33 and 35 is a constant 1 psi over the entire post-shot recording time. Data from the experimental digital station ( $35 \mathrm{~A}$ ) are not available. Pressure histories at elevations higher than station 35 can be explained as the result of ground motion. In particular, station 36 (just below the formation coupling plug, figure 2.6) shows only a slight, transient pressure change at detonation time. This suggests that the stations below it were influenced by the cavity pressure and that the fines layer immediately below the formation coupling plug acted as a relatively low permeability gas pressure barrier.

The pressure and radiation data are consistent with satisfactory containment. 


\subsection{Motion}

Explosion-induced histories of the motion measured on the DAUPHIN event are shown in figures 2.13-2.19. Characteristics of the associated motion and transducers are given in tables 2.1-2.3.

Both the accelerometer and velocity transducer at station 21 gave essentially the same wave form for about the first $250 \mathrm{~ms}$ suggesting that one or both were in error. Neither can be believed for this reason, though both are shown for completeness. The velocity gauge at station 22 yielded a signal that was very small in amplitude and with an anomalous wave form and should thus be disregarded. At station 23 (in the rigid plug near the top of the surface casing) the velocity transducer did not survive beyond zero time and at station 25 the accelerometer was dead pre-shot. Only the velocity transducers at stations 24, 61, and 71 seem to have yielded believable wave form data.

Early arrivals (prior to the ground motion) produced by motion of the emplacement pipe were seen in the acceleration records at all down-hole stations except station 21 (in the coarse stemming below the bottom plug). Since the pipe was coated with hydroseal in the regions of the TPE plugs at elevations higher than the drag ring, the pipe-induced motion at these higher stations was mitigated. The explosion-induced motion recorded in each of the rigid plugs and the ground surface was unremarkable. Figure 2.20 shows the motion arrival time as a function of range.

A stress gauge, bonded to the emplacement pipe near its top, (station 85) monitored the load on the pipe during emplacement and was recorded through the event and post-shot. Only the first $10 \mathrm{~s}$ are available and shown in figure 2.21 .

Relative displacement (separation) between the surface casing and the top plug and between the top plug and the underlying stemming was monitored by two Celesco ${ }^{\circledR}$ "fishing reel" type extensometers (stations 51 and 52) and one Shaveitz ${ }^{\circledR}$ LVDT (station 53). The first $10 \mathrm{~s}$ of separation history is shown in figure 2.22. Only station 52 (the separation of the top plug and underlying stemming) indicates extension. 

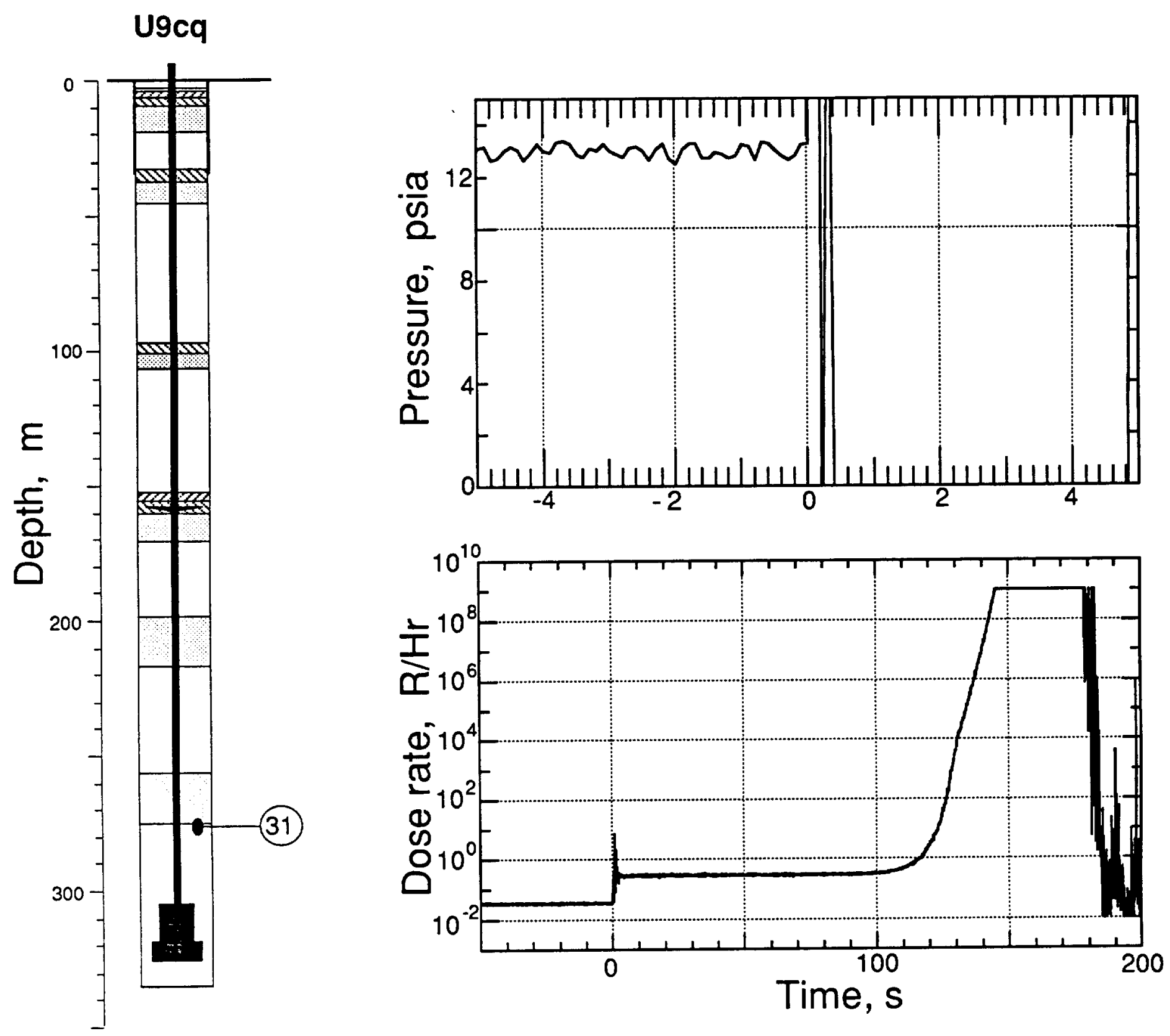

Figure 2.1 Pressure and radiation as monitored in the coarse stemming below the deep fines layer at a depth of $275.8 \mathrm{~m}$ (station 31 ). Note the time scale difference in the two plots. 

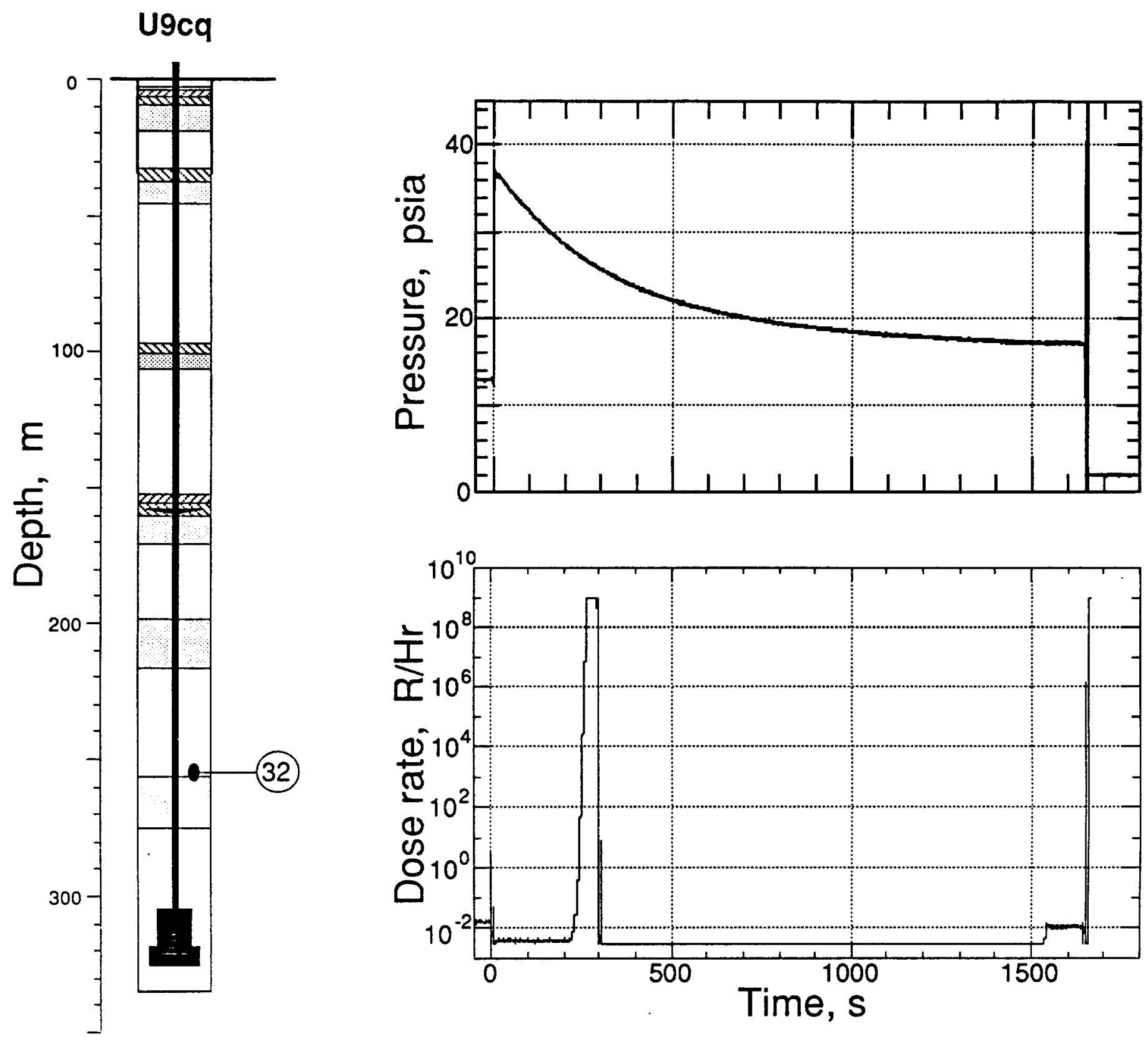

Figure 2.2 Pressure and radiation measured in the coarse stemming above the deep fines layer at a depth of $254.5 \mathrm{~m}$ (station 32). Signal loss of the radiation monitor occured shortly before $300 \mathrm{~s}$. 

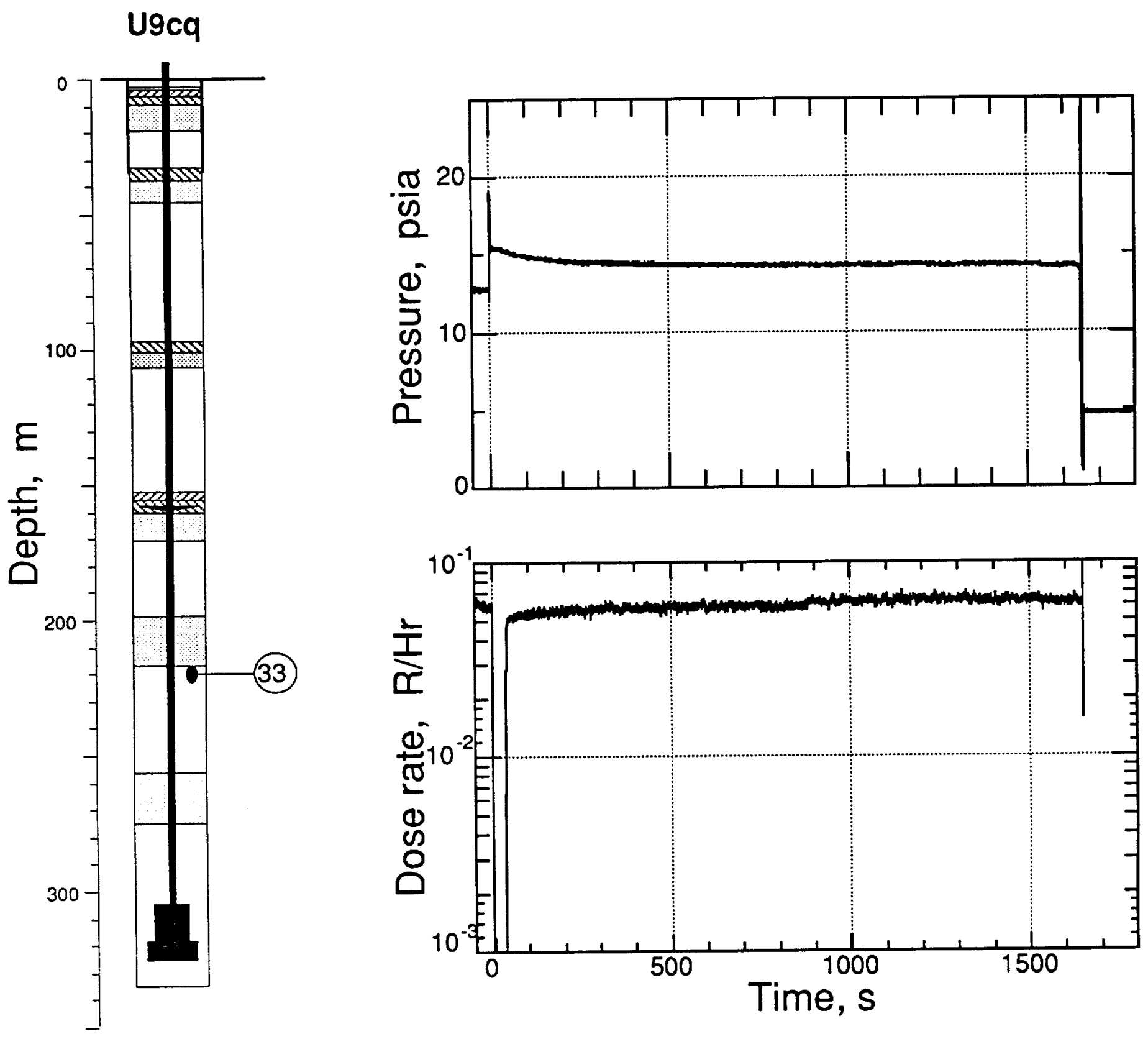

Figure 2.3 Pressure and radiation measured in the coarse stemming below the second fines layer at a depth of $219.5 \mathrm{~m}$ (station 33). 

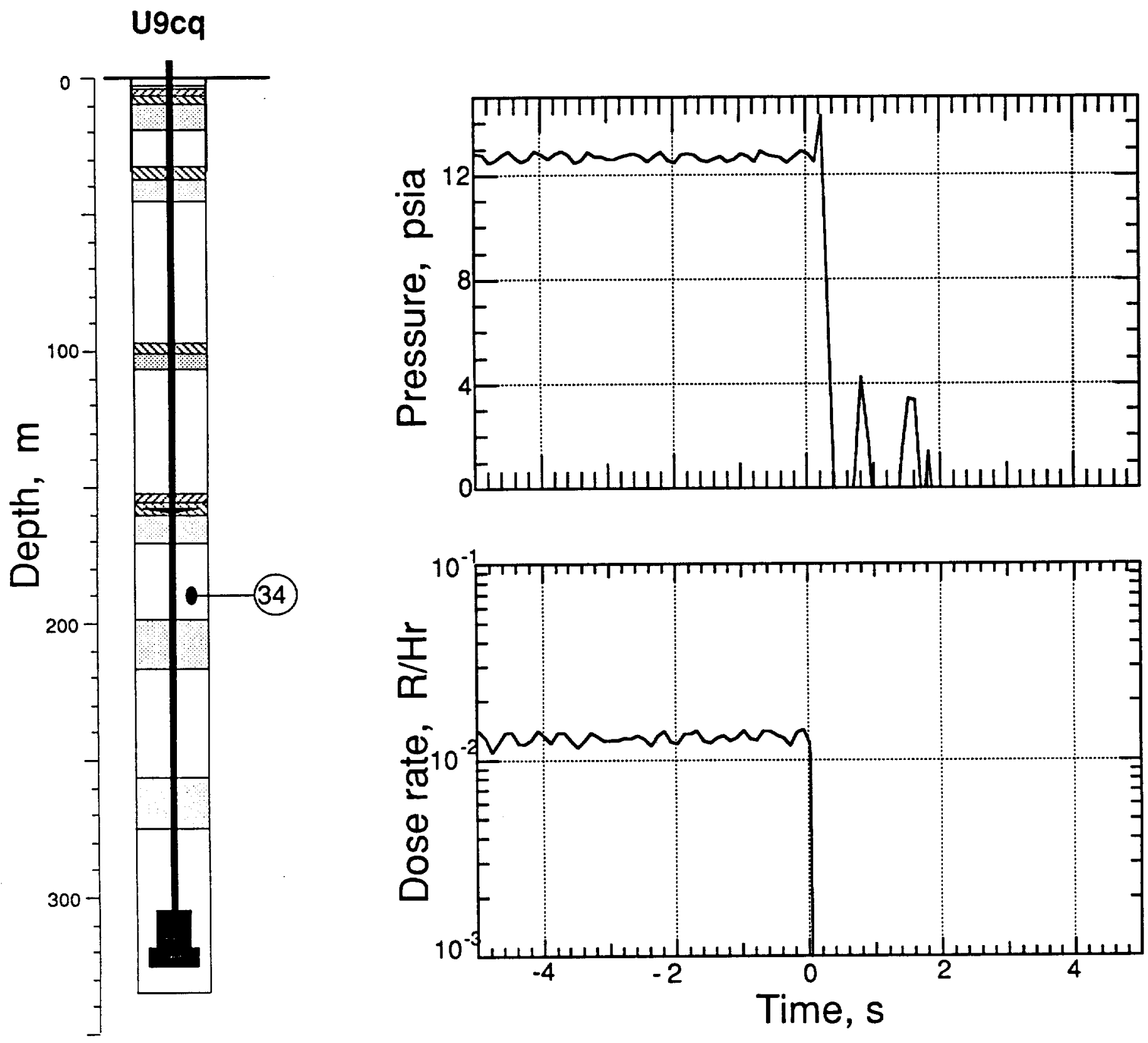

Figure 2.4 Pressure and radiation measured in the coarse stemming above the second fines layer at a depth of $192.0 \mathrm{~m}$ (station 34 ). 

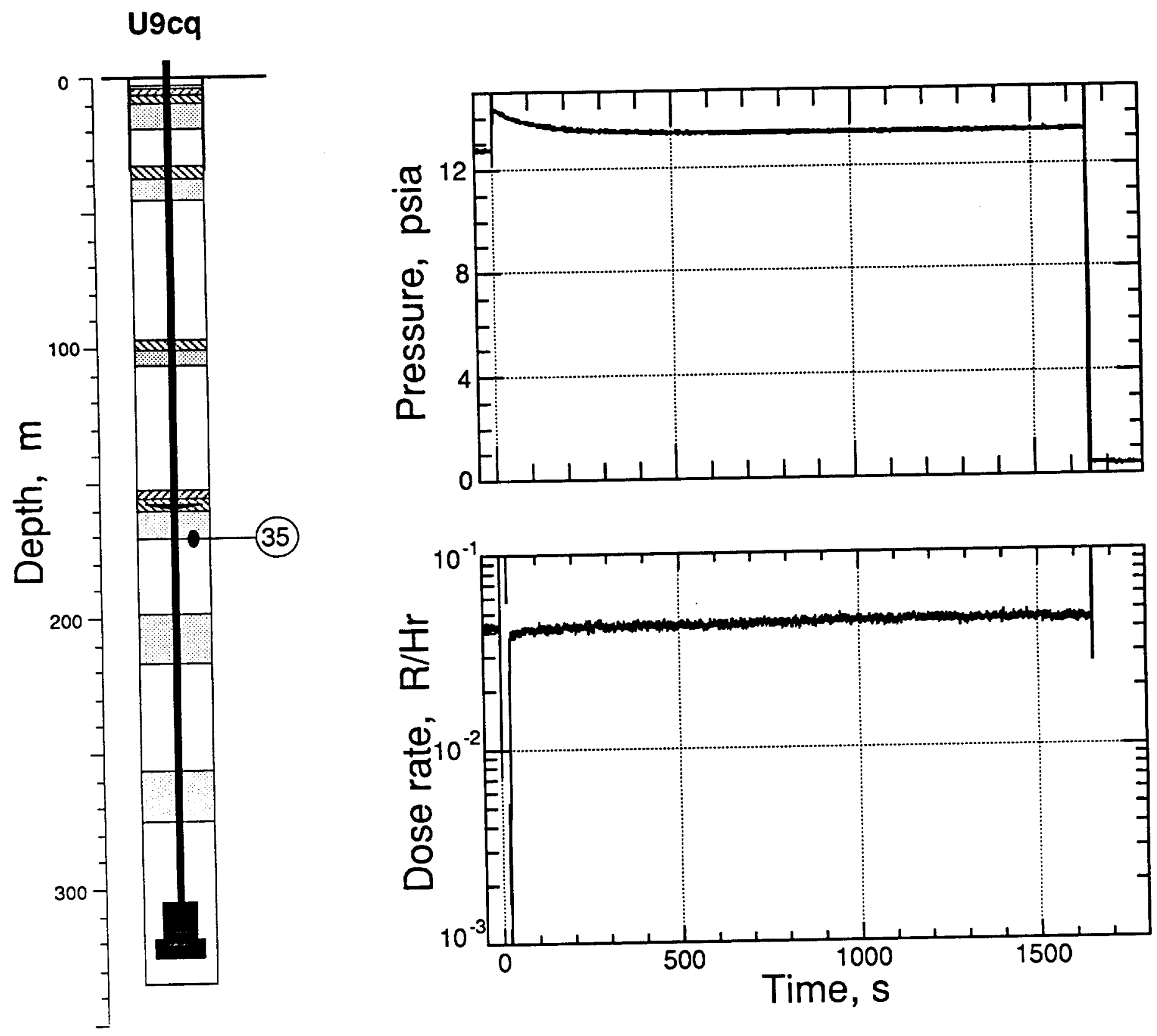

Figure 2.5 Pressure and radiation measured in the coarse stemming beneath the formation coupling plug at a depth of $170.7 \mathrm{~m}$ (station 35). 

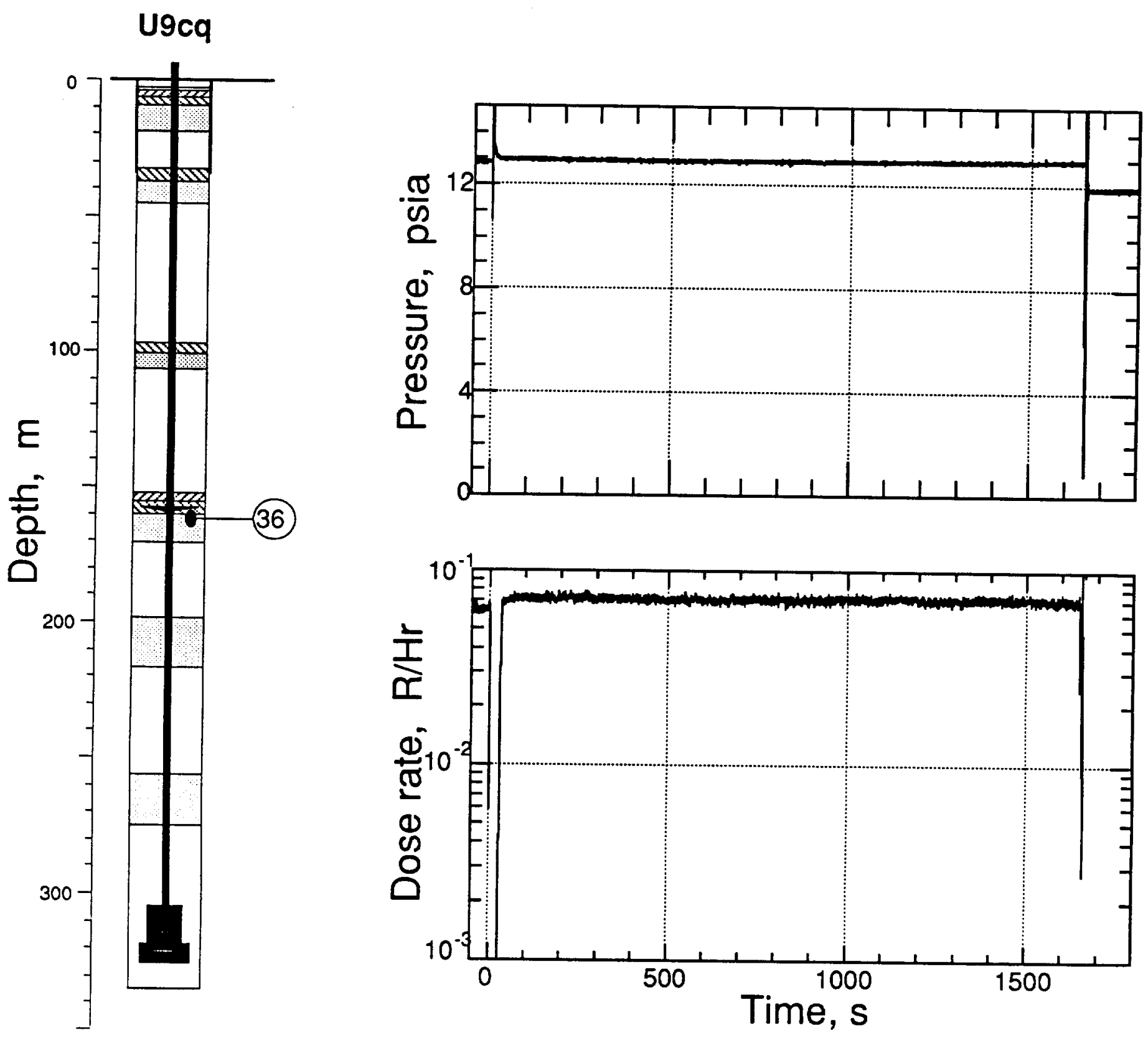

Figure 2.6 Pressure and radiation measured in the coarse stemming above the formation coupling plug at a depth of $162.2 \mathrm{~m}$ (station 36 ). 

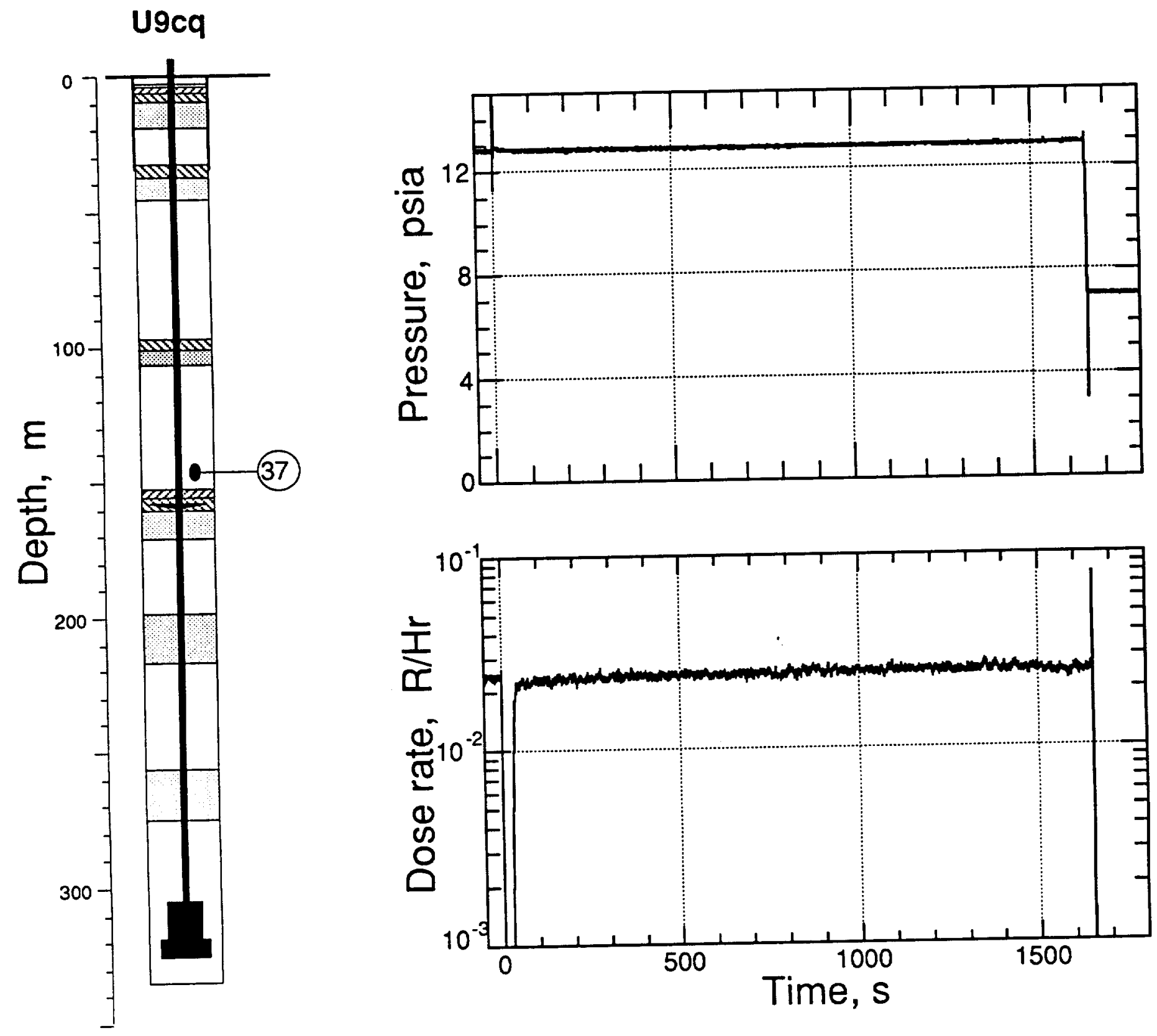

Figure 2.7 Pressure and radiation measured in the coarse stemming above the fines layer at a depth of $146.3 \mathrm{~m}$ (station 37). 

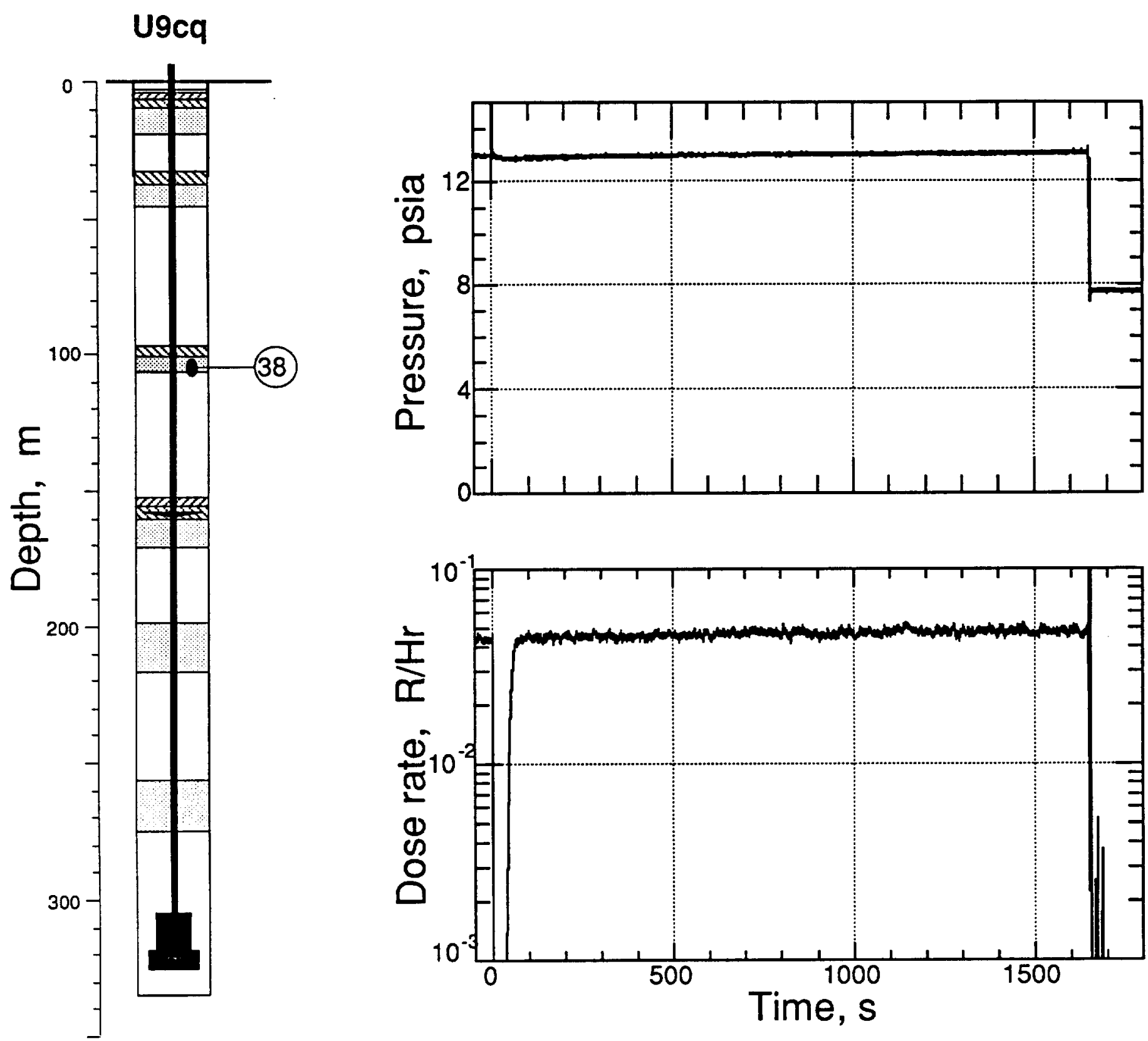

Figure 2.8 Pressure and radiation measured in the coarse stemming below the second rigid plug at a depth of $105.2 \mathrm{~m}$ (station 38). 

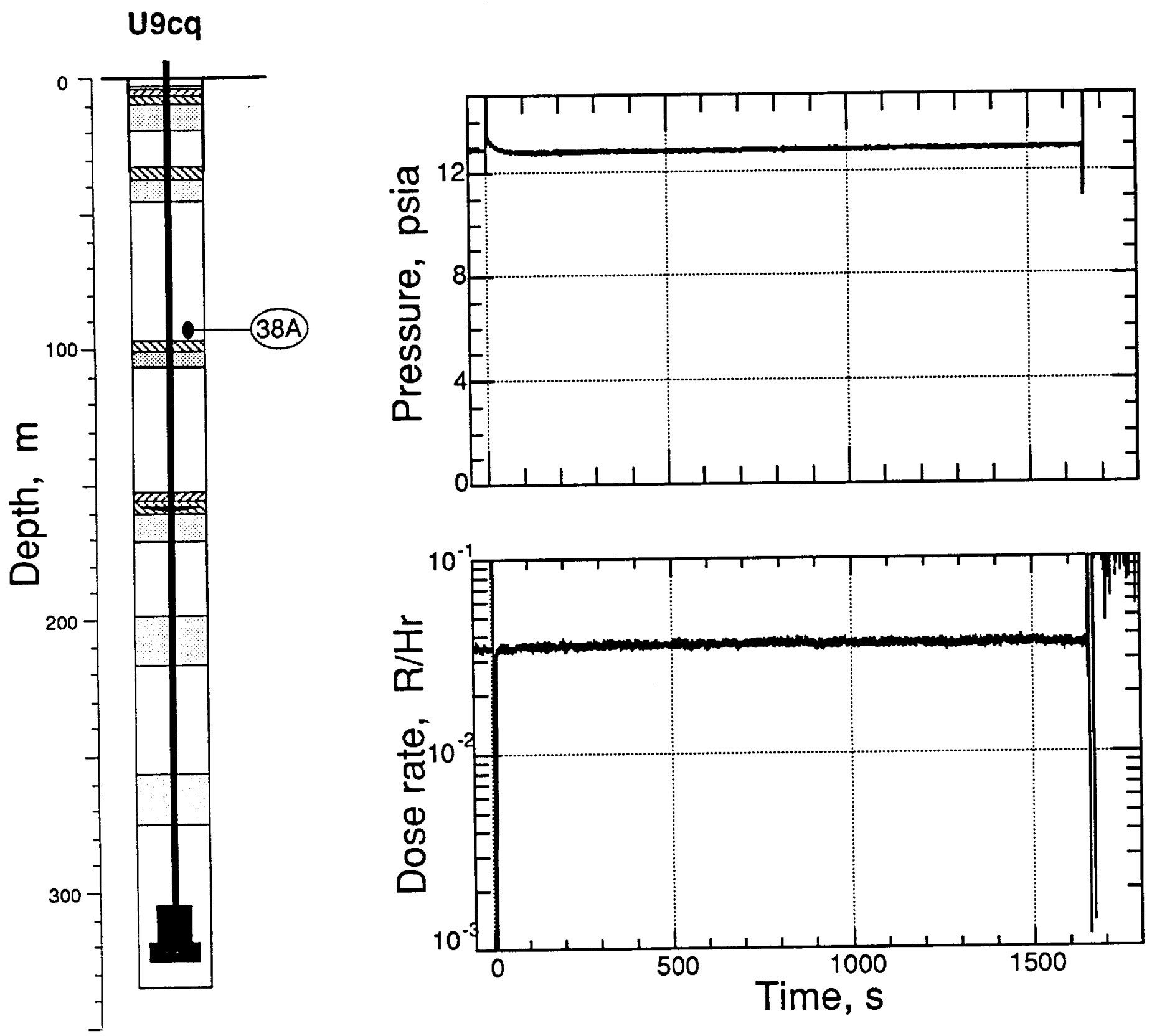

Figure 2.9 Pressure and radiation measured in the coarse stemming above the second rigid plug at a depth of $93.0 \mathrm{~m}$ (station 38A). 

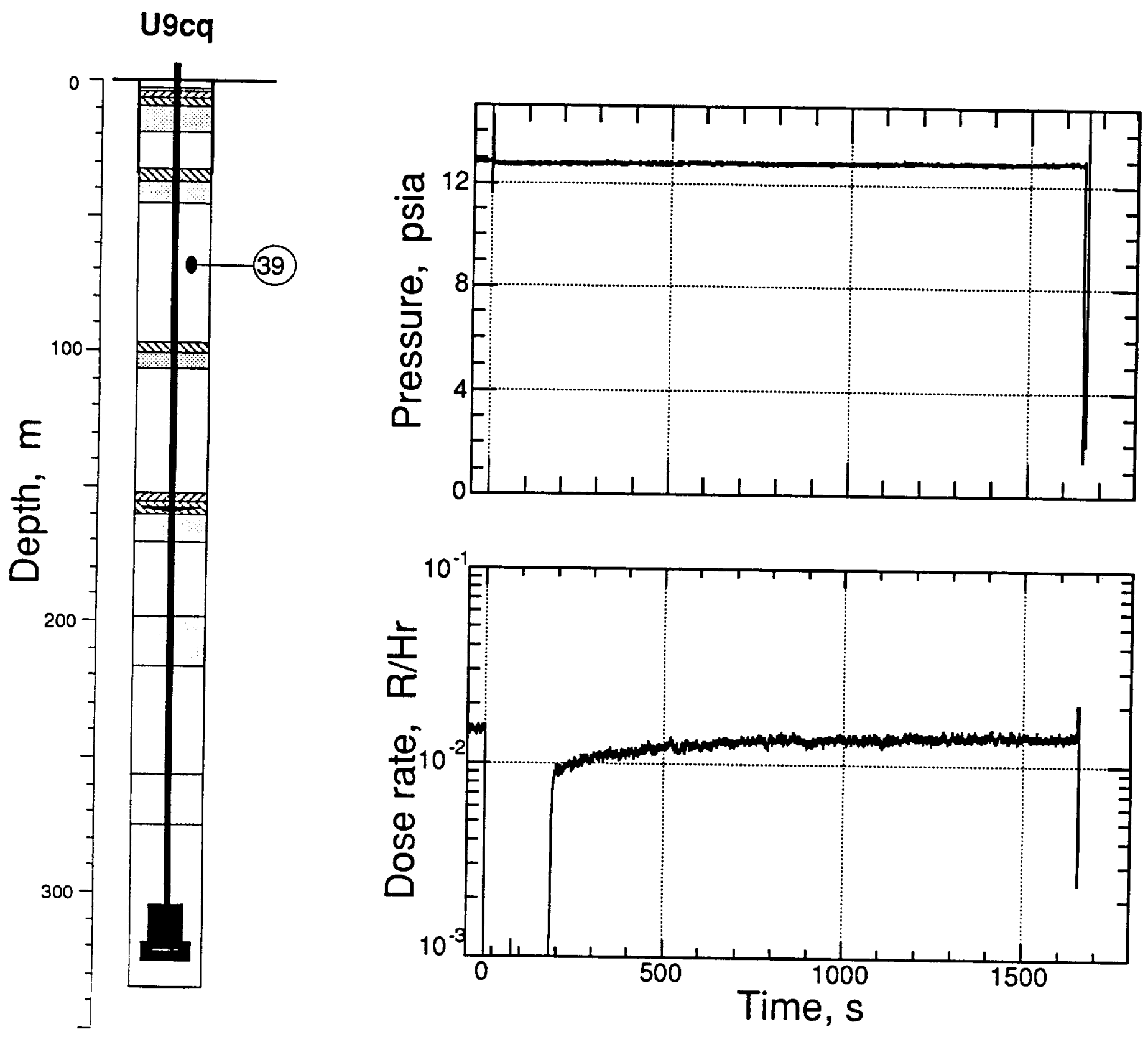

Figure 2.10 Pressure and radiation measured in the coarse stemming beneath the top plug at a depth of $68.6 \mathrm{~m}$ (station 39). 

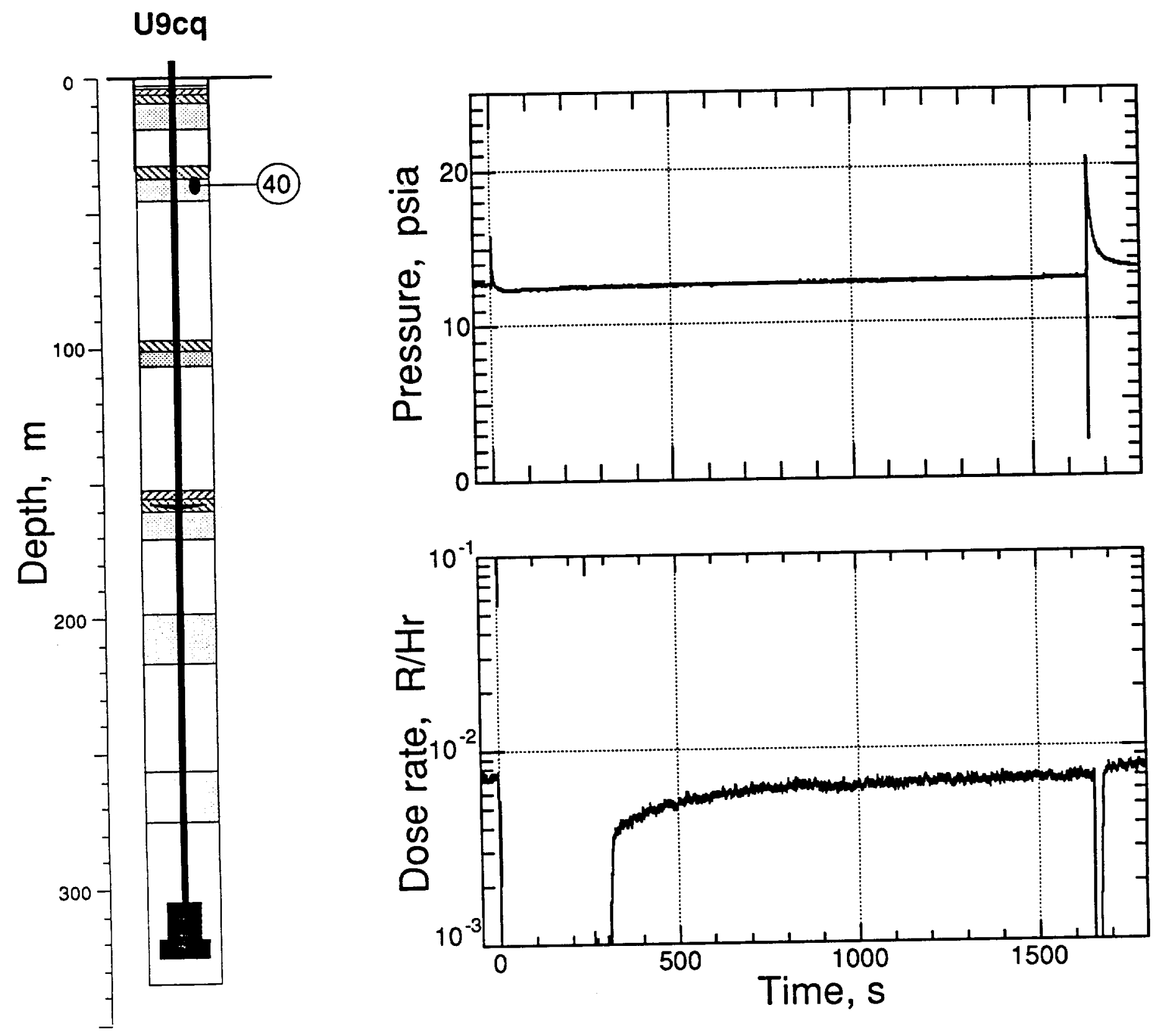

Figure 2.11 Pressure and radiation measured in the coarse stemming beneath the top plug at a depth of $39.6 \mathrm{~m}$ (station 40 ). 

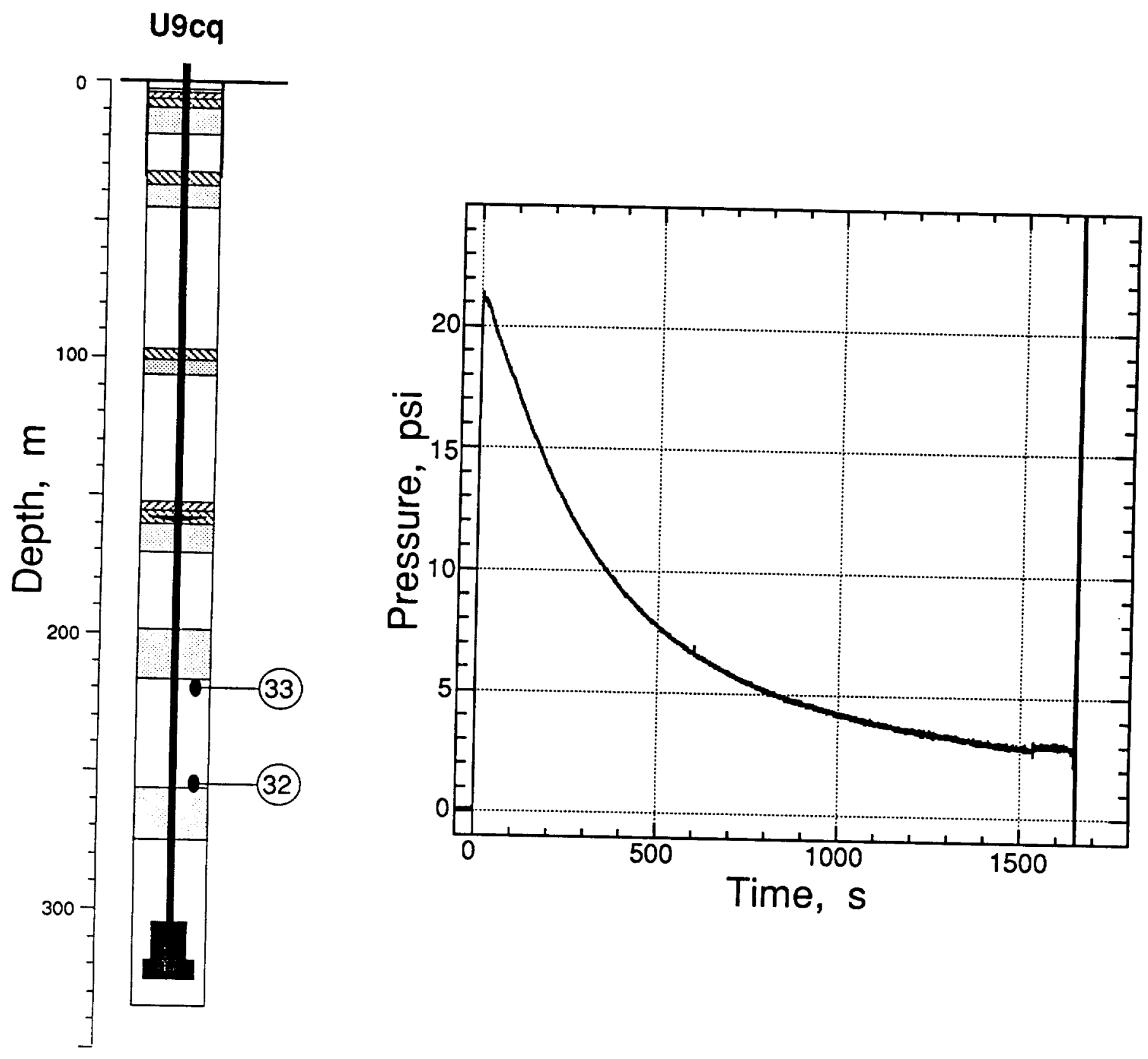

Figure 2.12 Difference in pressure between stations 32 and 33 (across a coarse stemming layer). 

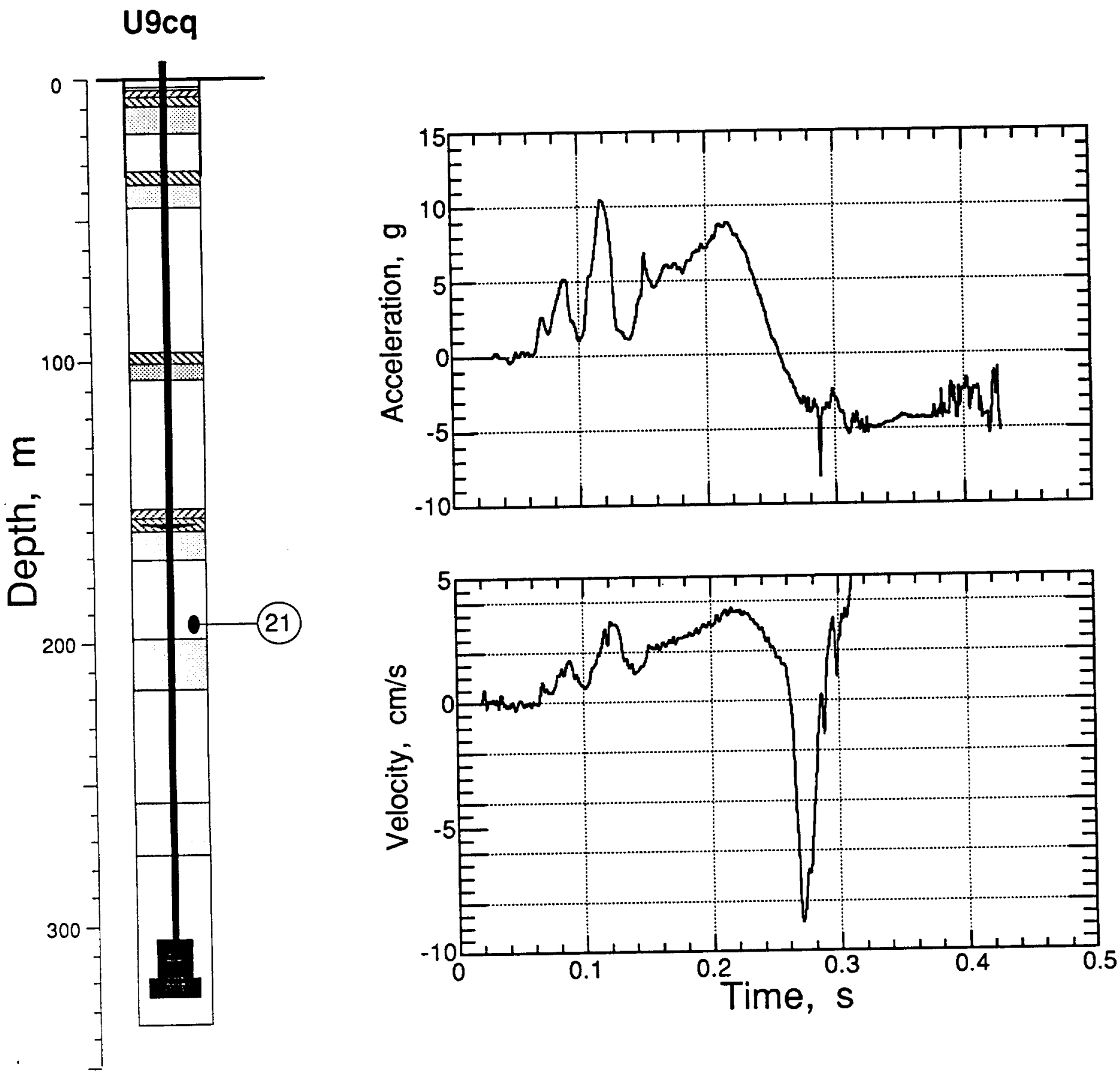

Figure 2.13 Explosion-induced vertical motion of the coarse stemming $33.5 \mathrm{~m}$ below the formation coupling plug (station 21 , at a depth of $193.6 \mathrm{~m}$ ). Note the similarity for the first $250 \mathrm{~ms}$ of the wave forms of both the accelerometer and the velocity transducer. This tends to invalidate both records. 

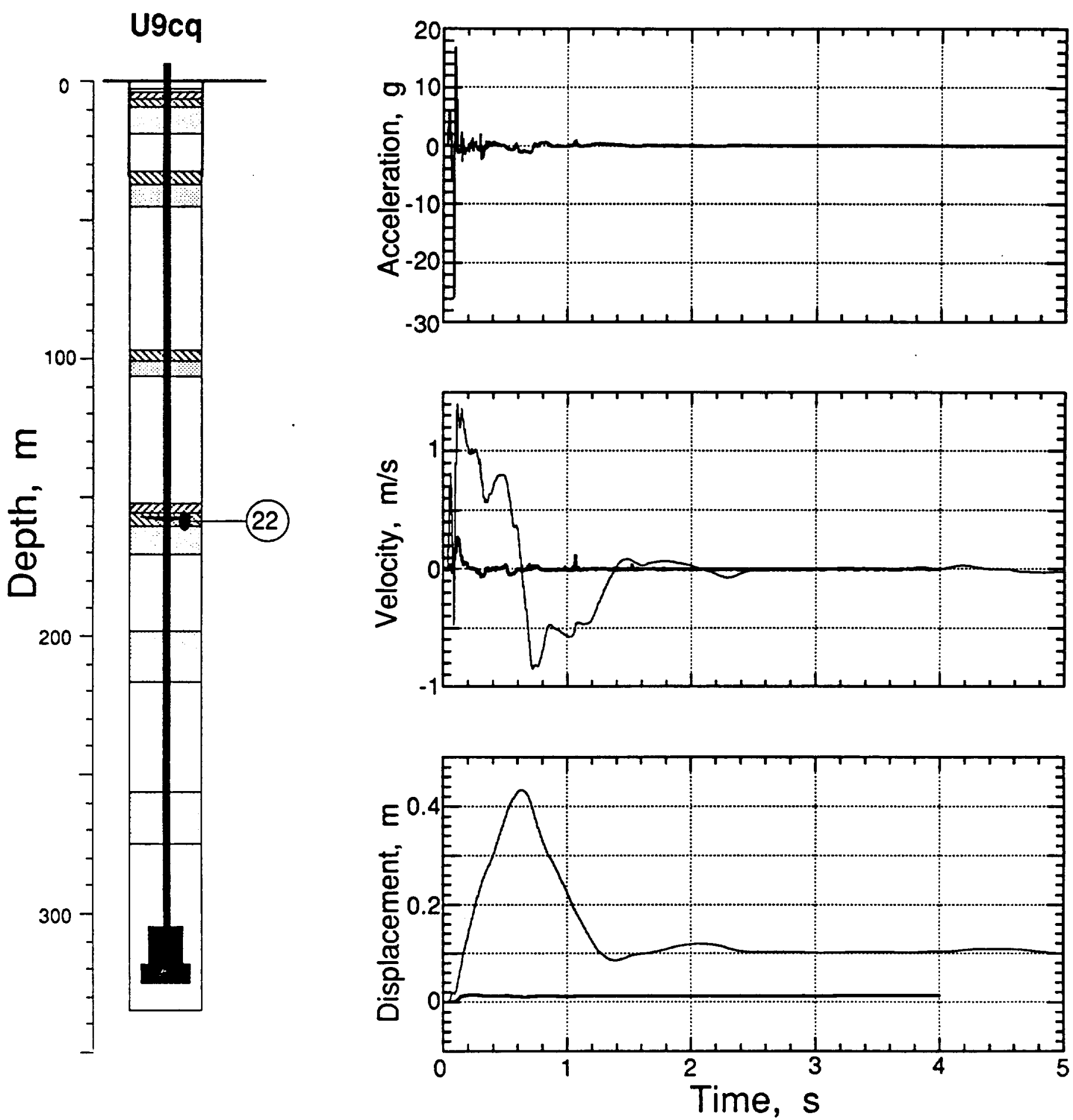

Figure 2.14 Explosion-induced vertical motion of the formation coupling plug (station 22, at a depth of $158.5 \mathrm{~m}$ ). When there are two traces in a single plot, the heavier is derived from the velocity transducer. Comparing these records with those of station 23 (figure 2.15) suggests that the velocimeter data of station 22 be ignored. The acceleration at early time shows strong motion induced by the emplacement pipe and the drag ring. 

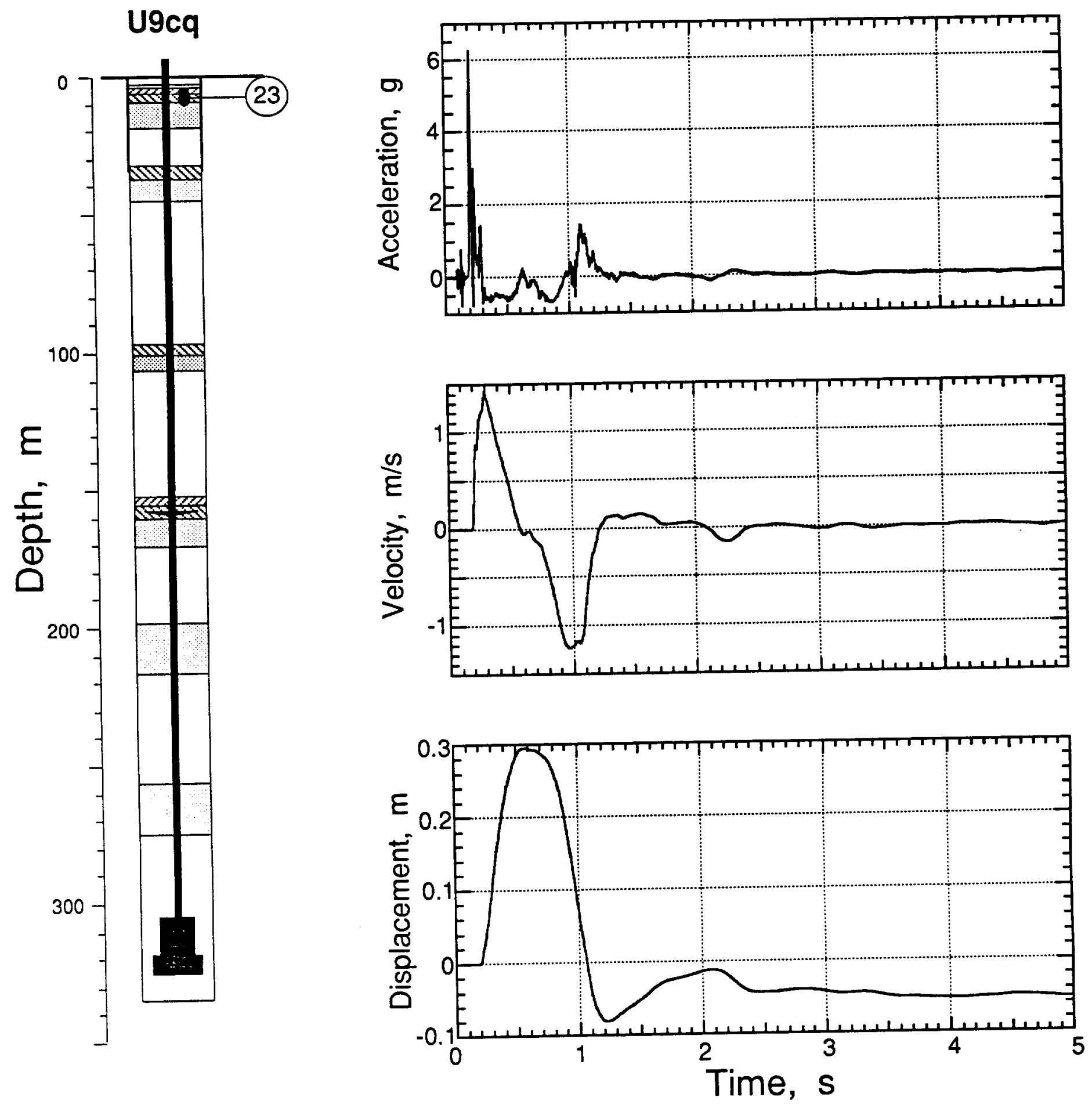

Finure 215 Explosion-induced vertical motion of the rigid plug within and near the top of the

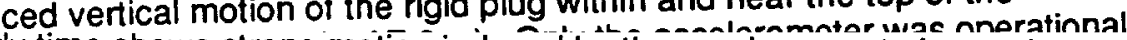
the drag ring. 

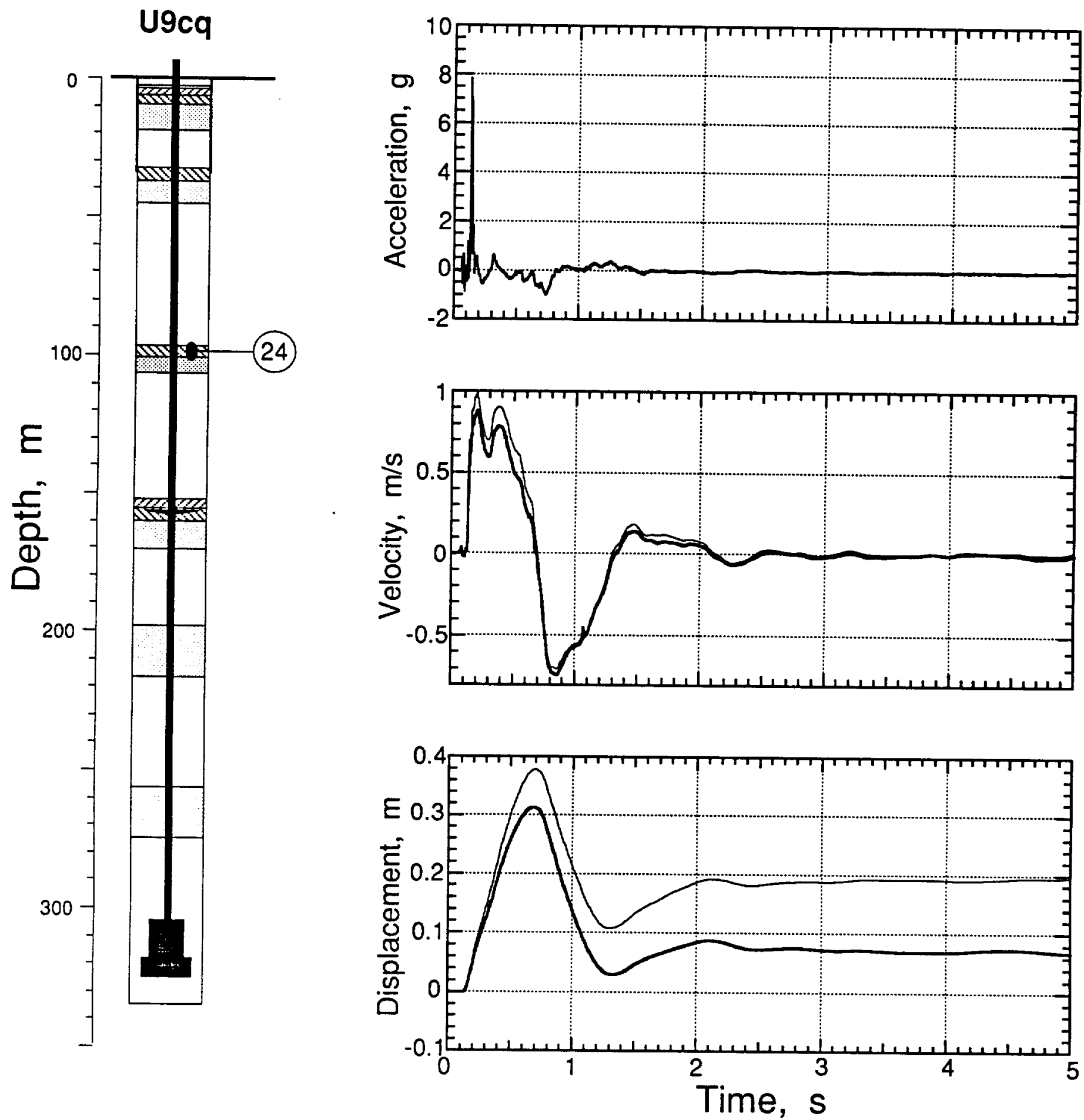

Figure 2.16 Explosion-induced vertical motion of the second rigid plug (station 24 at a depth of $98.5 \mathrm{~m})$. When there are two traces in a single plot, the heavier is derived from the velocity transducer. 

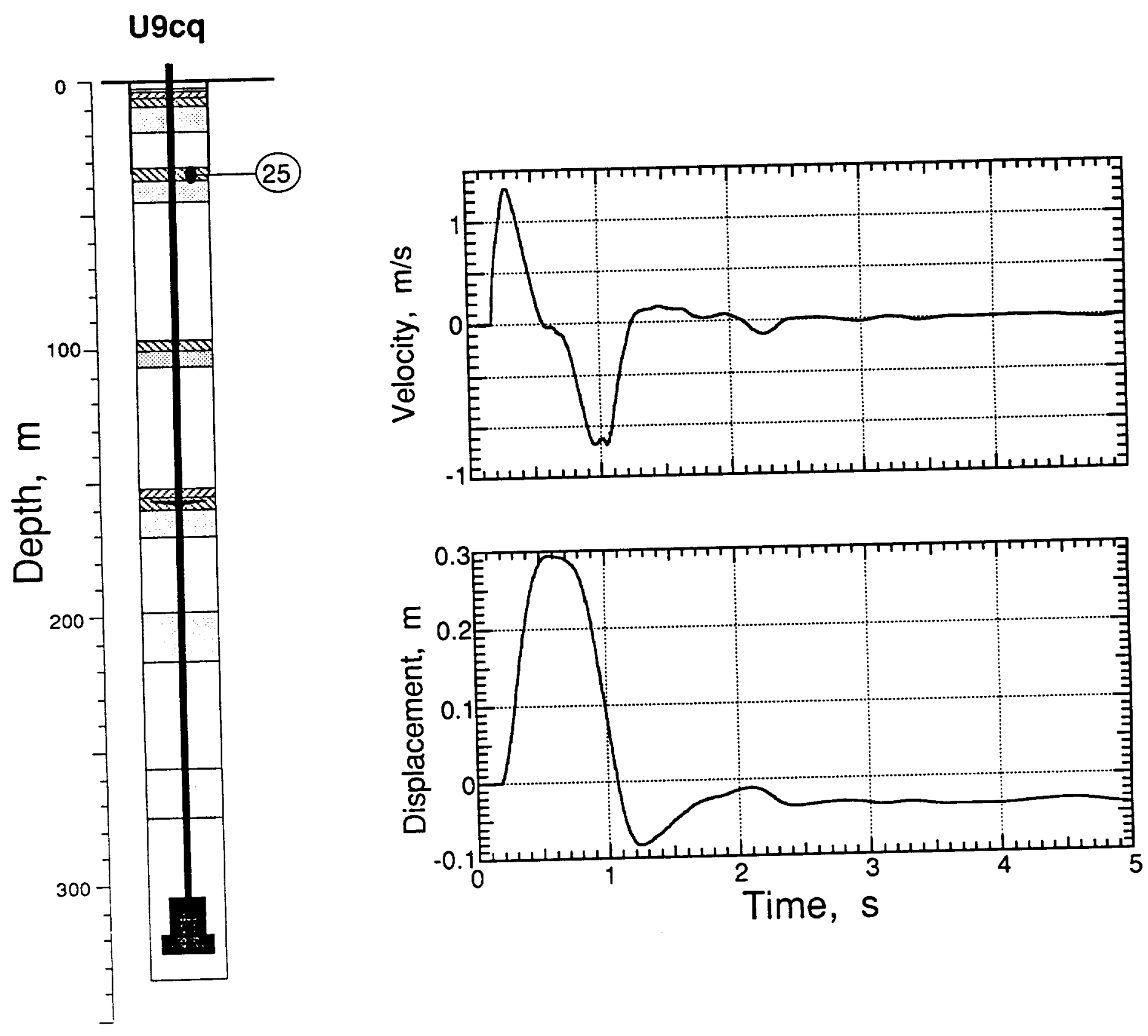

Figure 2.17 Explosion-induced vertical motion of the third rigid plug, extending part way in to the surface casing (station 25 , at a depth of $36.0 \mathrm{~m}$ ). The accelerometer at this location did not record. 

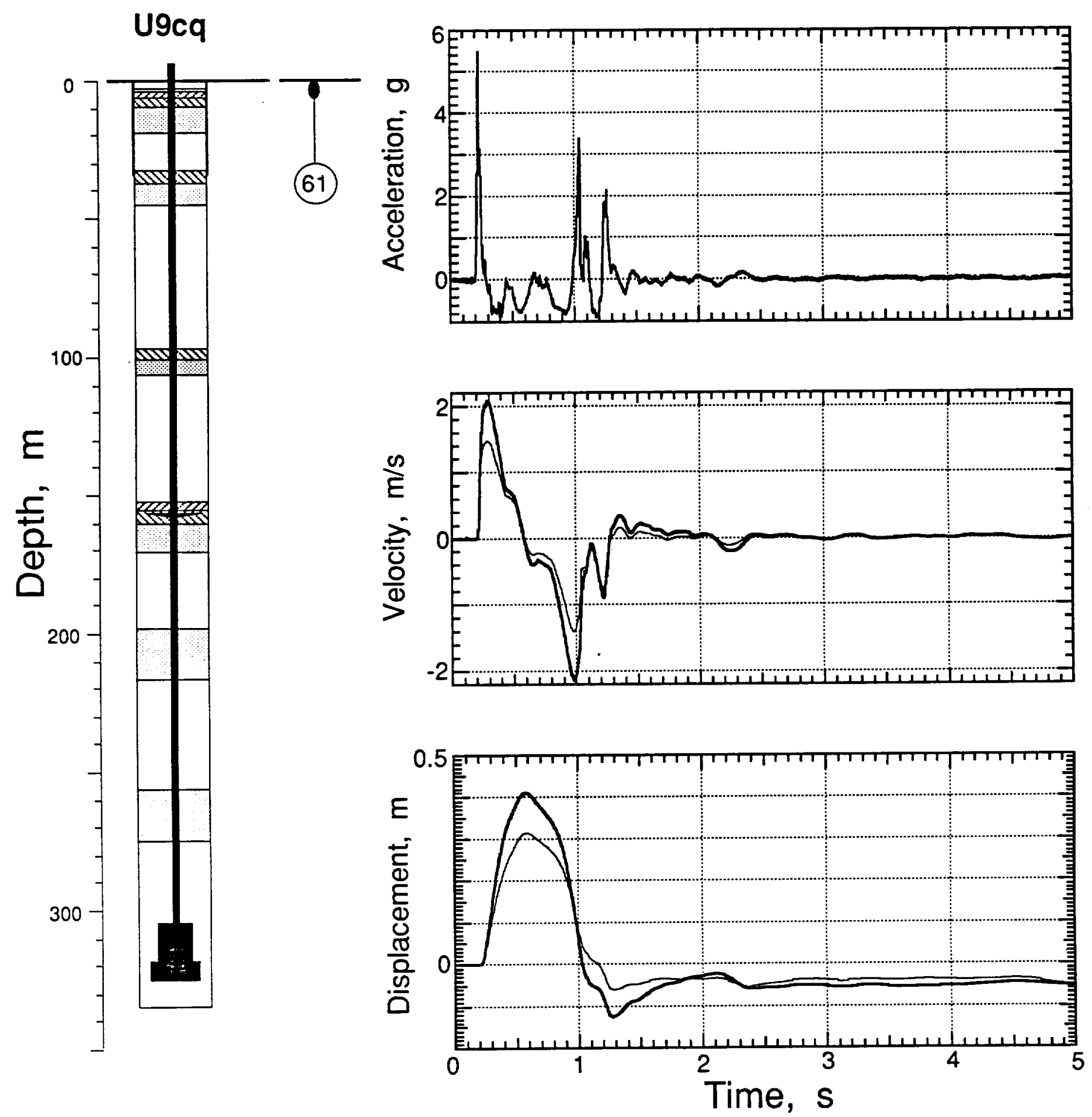

Figure 2.18 Explosion-induced vertical motion of the ground surface at a depth of $0.9 \mathrm{~m}$ and horizontal range of $15.24 \mathrm{~m}$ (station 61 ). When there are two traces in a single plot, the heavier is derived from the velocity transducer. 

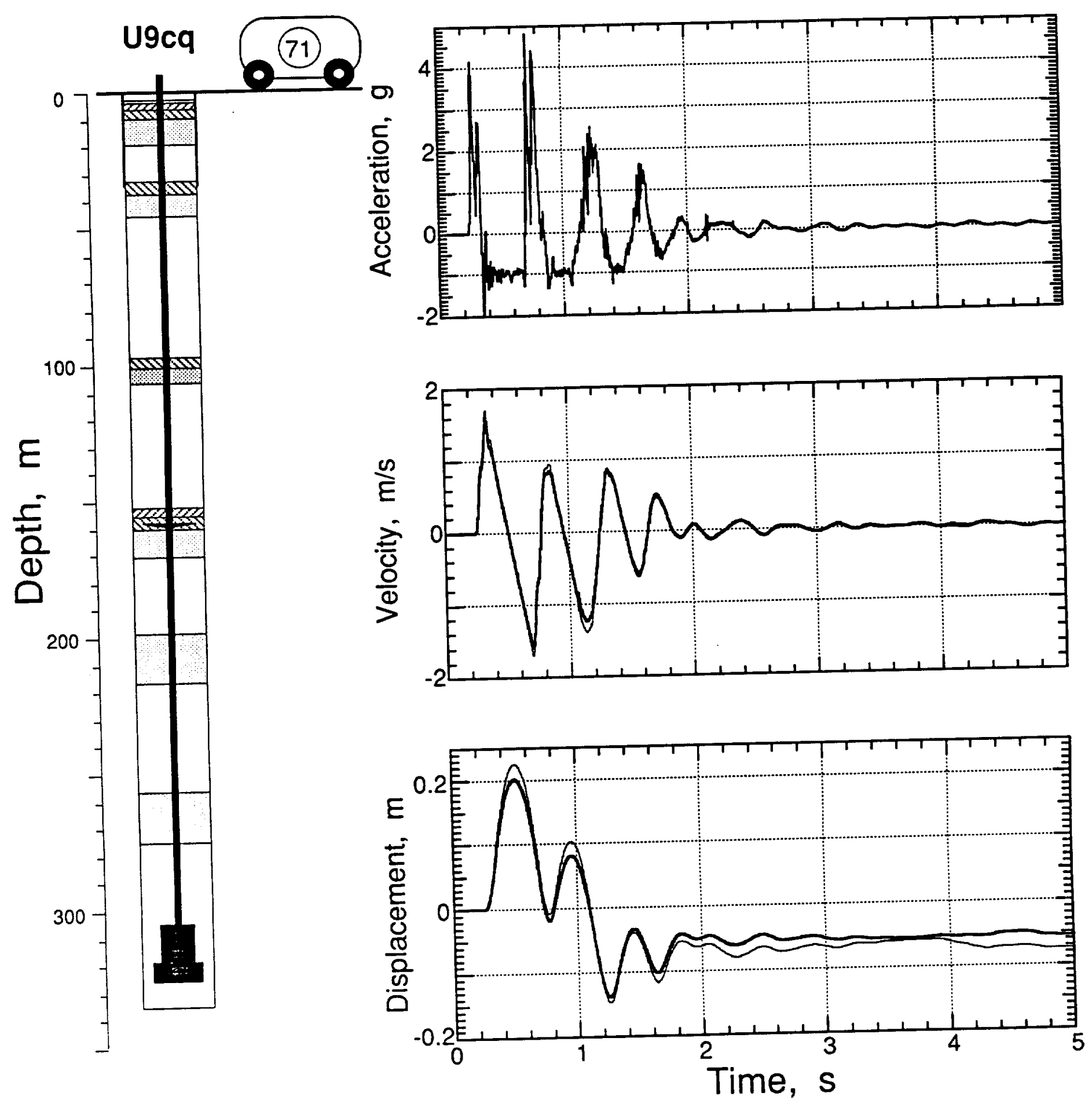

Figure 2.19 Explosion-induced vertical motion of the recording trailer (station 71 ). When there are two traces in a single plot, the heavier is derived from the velocity transducer. 


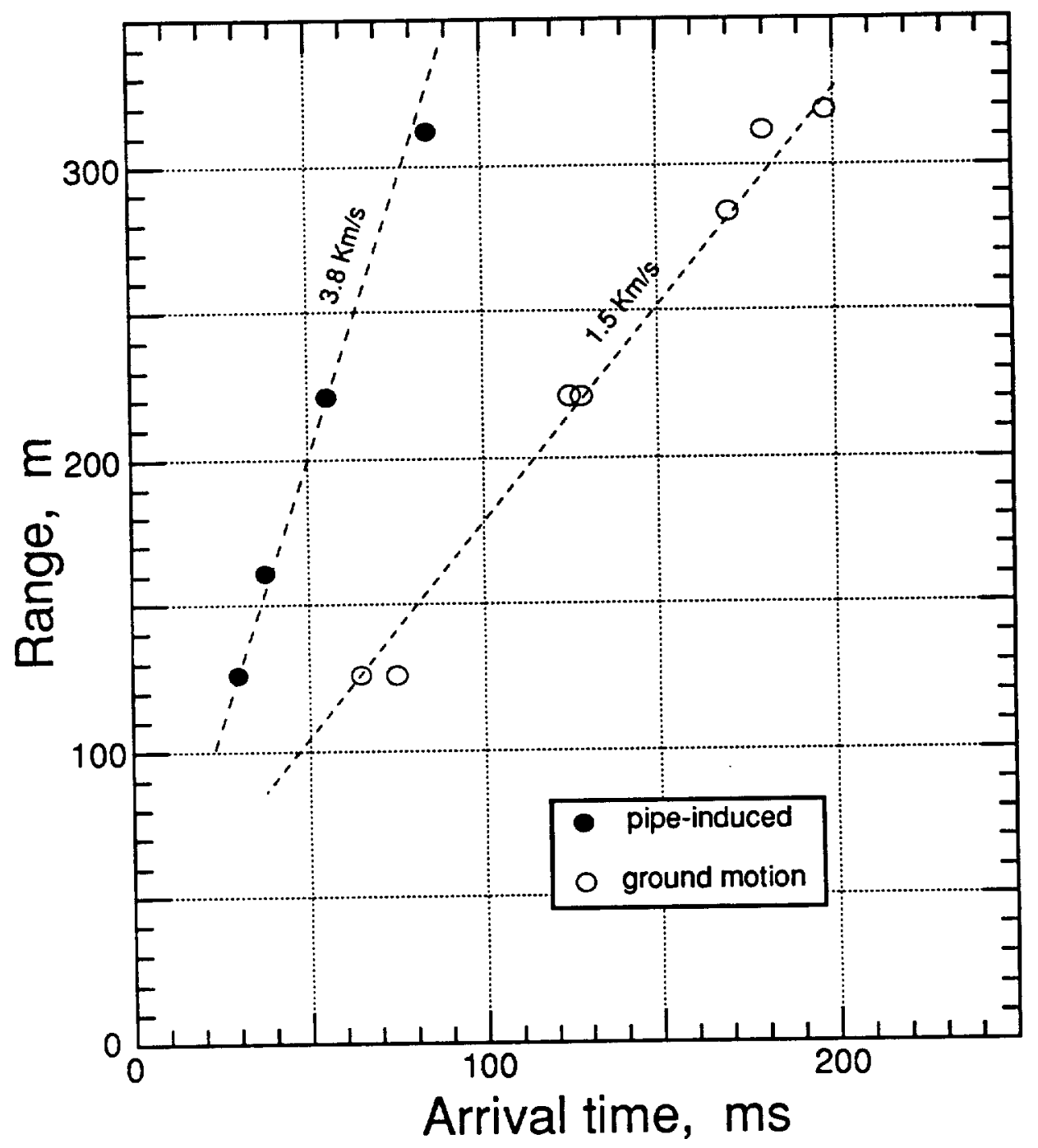

Figure 2.20 First motion arrival times versus range. 

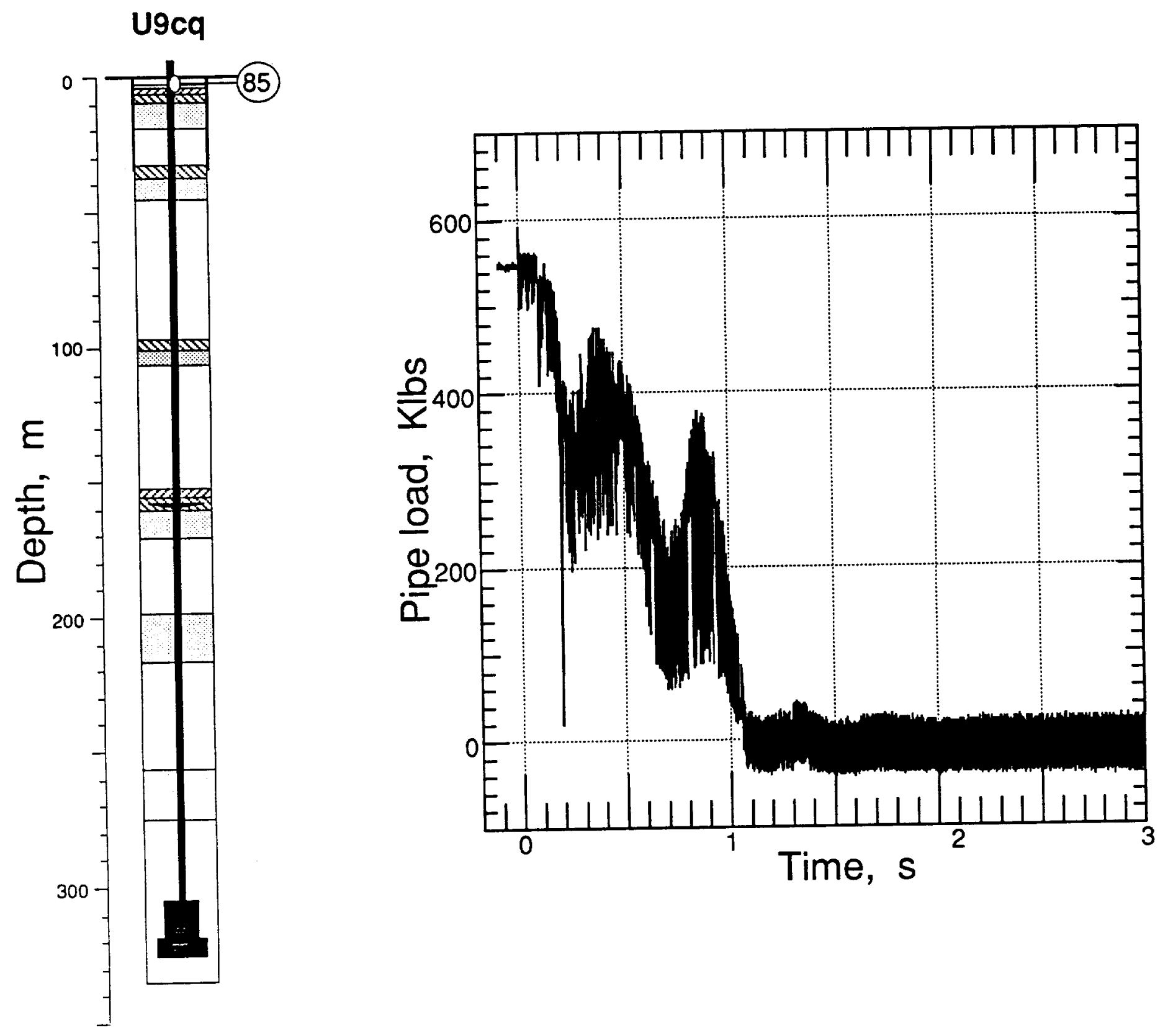

Figure 2.21 Strain (load) measured on the emplacement pipe near its top. 


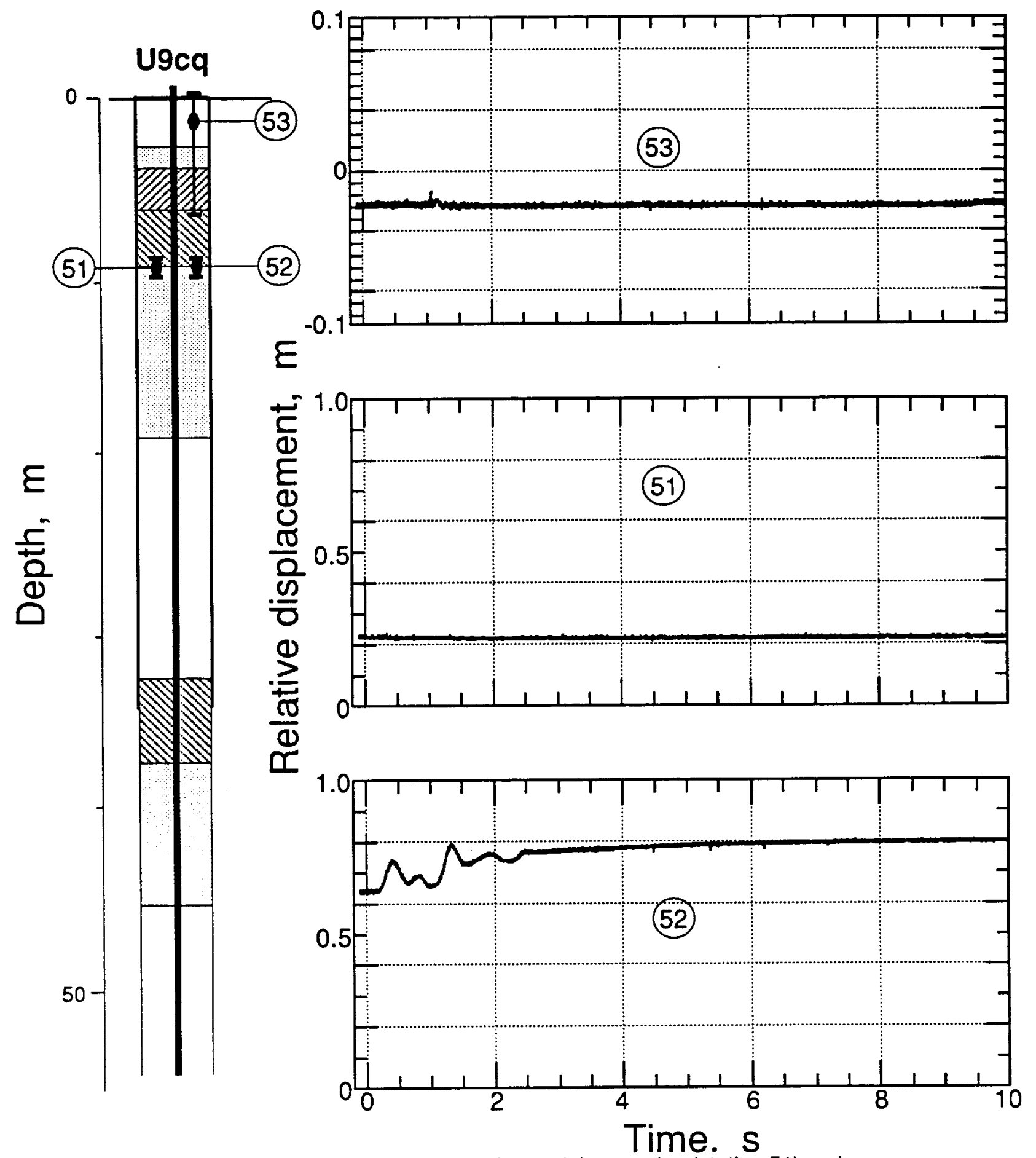

Figure 2.22 Separation between the surface casing and the top plug (station 51) and between the top plug and lower stemming (stations 52 and 53). Station 53 was an LVDT displacement transducer while stations 51 and 52 contained reel type extensometers. 


\section{Table 2.1 Summary of Containment-Related Motlon}

\begin{tabular}{|c|c|c|c|c|c|c|}
\hline Gauge & $\begin{array}{c}\text { Slant Range } \\
\text { (m) }\end{array}$ & $\begin{array}{l}\text { Arrival Time } \\
\quad(\mathrm{ms})\end{array}$ & $\begin{array}{l}\text { Acceleration } \\
\text { Peak (g) }\end{array}$ & $\begin{array}{c}\text { Velocity Peak } \\
(\mathrm{m} / \mathrm{s})\end{array}$ & $\begin{array}{l}\text { Displacement } \\
\text { Peak (cm) }\end{array}$ & $\begin{array}{l}\text { Displacement } \\
\text { Residual (cm) }\end{array}$ \\
\hline $21 a v$ & 125.9 & $30^{(a)}, 65$ & (b) & - & - & - \\
\hline 21uv & 125.9 & 75 & (b) & - & - & $=$ \\
\hline $22 a v$ & 161 & $38^{(a)}$ & 17 & 1.4 & 43 & 10 \\
\hline 22uv & 161 & 38 (a) & - & (b) & - & - \\
\hline $23 a v$ & 311.9 & $85^{(a)}, 180$ & 6.3 & 1.4 & 29 & -4 \\
\hline $23 u v$ & (c) & 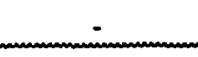 & تستس & نستس & ت & $=$ \\
\hline $24 a v$ & 221.0 & $56^{(a)}, 125$ & 7.8 & 0.98 & 38 & 18 \\
\hline 24uv & 221.0 & $56(a), 128$ & - & 0.88 & 31 & 8 \\
\hline $25 a v$ & (c) & - & $\cdot$ & - & - & - \\
\hline $25 u v$ & 283.8 & 170 & ستر & 1.4 & 29 & -3 \\
\hline $61 a v$ & 318.6 & 198 & 5.5 & 1.47 & 31 & -4 \\
\hline 61uv & 318.6 & - & - & 2.1 & 41 & -5 \\
\hline 71 av & $358(d)$ & 236 & 4.2 & 1.70 & 22.5 & -8 \\
\hline 71uv & $358^{(d)}$ & - & - & 1.58 & 20 & -5 \\
\hline
\end{tabular}

(a) Pipe-induced motion.

(b) Anomalous signal: disregard these records.

(c) Transducer lost at zero time.

(d) Approximate: station mounted in recording trailer. 
Iable 2.2 Containment-Related Accelerometer Characteristics

\begin{tabular}{lccc} 
Gauge & $\begin{array}{c}\text { Natural Frequency } \\
(\mathrm{Hz})\end{array}$ & Damping Ratio & $\begin{array}{c}\text { System Range } \\
\left(g^{\prime} \mathbf{s}\right)\end{array}$ \\
\cline { 2 - 4 } 21av & 250 & 0.75 & 10 \\
22av & 500 & 0.65 & 50 \\
23av & 400 & 0.65 & 20 \\
24av & 530 & 0.75 & 30 \\
25av & 390 & 0.65 & 20 \\
61av & 550 & 0.65 & 30 \\
71av & 220 & 0.65 & 10
\end{tabular}

Table 2.3 Containment-Related Velocimeter Characteristics

\begin{tabular}{|c|c|c|c|c|c|}
\hline Gauge & $\begin{array}{c}\text { Natural } \\
\text { Frequency } \\
(\mathrm{Hz})\end{array}$ & $\begin{array}{c}\text { Time to } 0.5 \\
\text { Amplitude } \\
\text { (s) }\end{array}$ & $\begin{array}{c}\text { Calibration } \\
\text { Temperature } \\
\left.\text { ( }{ }^{\circ} \mathrm{F}\right)\end{array}$ & $\begin{array}{c}\text { Operate } \\
\text { Temperature } \\
\text { (०F) }\end{array}$ & $\begin{array}{c}\text { System } \\
\text { Range } \\
\text { (ms) }\end{array}$ \\
\hline $21 u v$ & 3.6 & 7.45 & 74.55 & 75.4 & 1.5 \\
\hline $22 u v$ & 3.5 & 8.78 & 74.3 & 94.4 & 1.5 \\
\hline $23 u v$ & 3.2 & 9.78 & 74.7 & 107.2 & 1.5 \\
\hline $24 u v$ & 3.57 & 13.7 & 73.5 & 93.9 & 1.5 \\
\hline $25 u v$ & 3.61 & 8.3 & 74.3 & 103.9 & 1.5 \\
\hline 61uv & 3.56 & 8.5 & 74.3 & 62.1 & 2 \\
\hline $71 u v$ & 4.0 & 20.4 & 74.1 & 67.1 & 2 \\
\hline
\end{tabular}




\section{Collapse ohenomena}

\subsection{Motion}

Collapse-induced histories of the motion measured on the DAUPHIN event are shown in figures 3.1-3.6. Collapse reached the ground surface $1652 \mathrm{~s}$ after detonation with slap-down occurring about $1.3 \mathrm{~s}$ later. Station 21 was likely damaged by the detonation and the data of figure 3.1 are shown for completeness and timing only. The other collapse motion signals show an oscillation following the collapse. During subsequent investigation this was found to be due to an oscillation in the recording system which altered the channel sensitivities. Integration of these signals is highly suspect. Collapse motion of the recording trailer (station 71) was not observed and thus not shown.

\subsection{Radiation and Pressure}

Pressure and radiation histories recorded during the $20 \mathrm{~s}$ of the collapse activity are shown in figures $3.7-3.15$. Stations 31 and 34 are not represented as they were lost at early time.

Progression of the collapse is shown in figure 3.16 by reading, by hand, the open condition of the D-cable. Pulses are transmitted down the cable at a rate of once every $0.74 \mathrm{~s}$, giving a limit to the timing accuracy of the occurrence of the open condition. Also plotted are most of the pressure records. Missing, only for clarity, are the data from station 37 . 

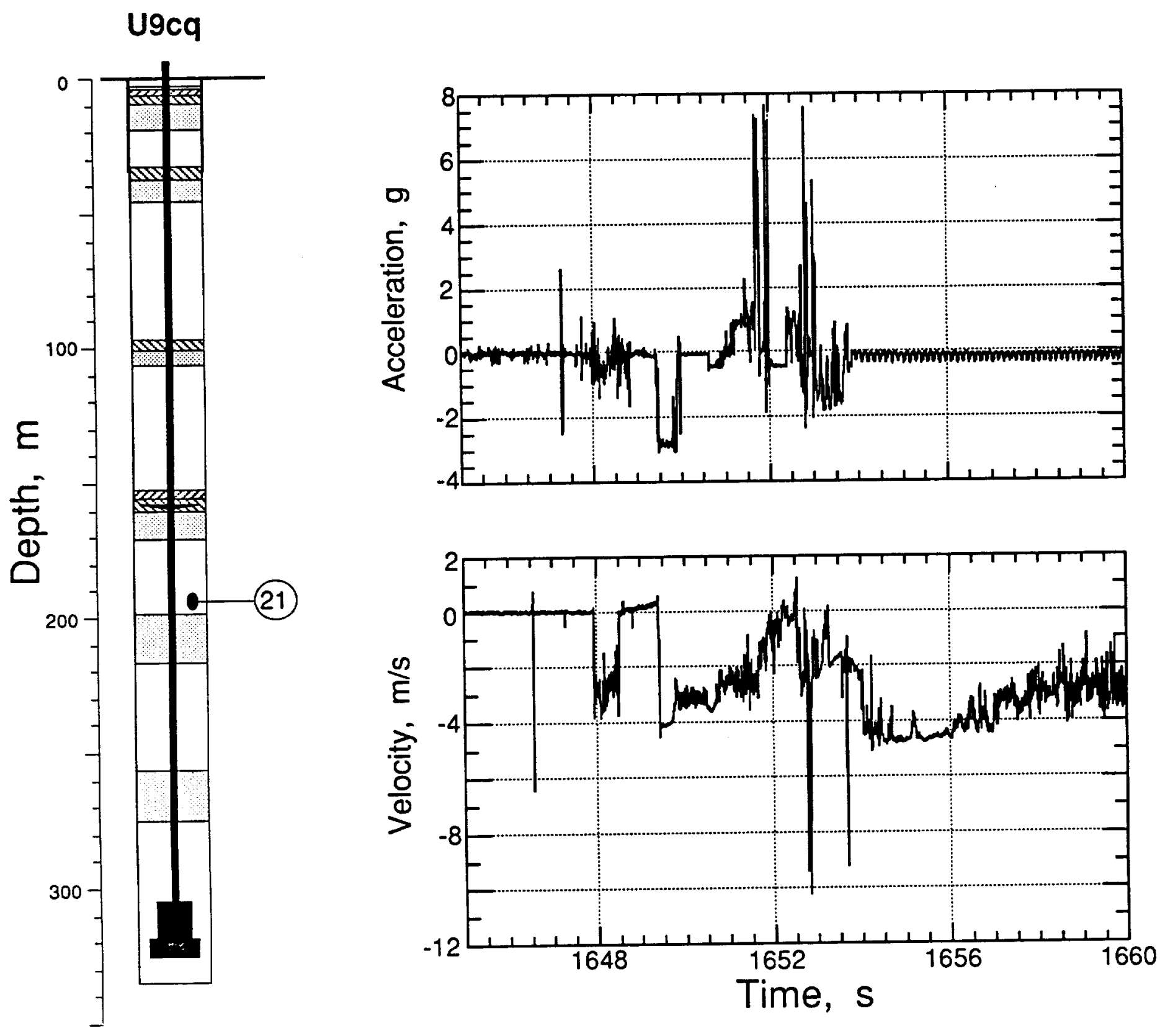

Figure 3.1 Collapse-induced vertical motion of the coarse stemming $33.5 \mathrm{~m}$ below the formation coupling plug (station 21, at a depth of $193.6 \mathrm{~m}$ ). These data are shown for timing information only. 

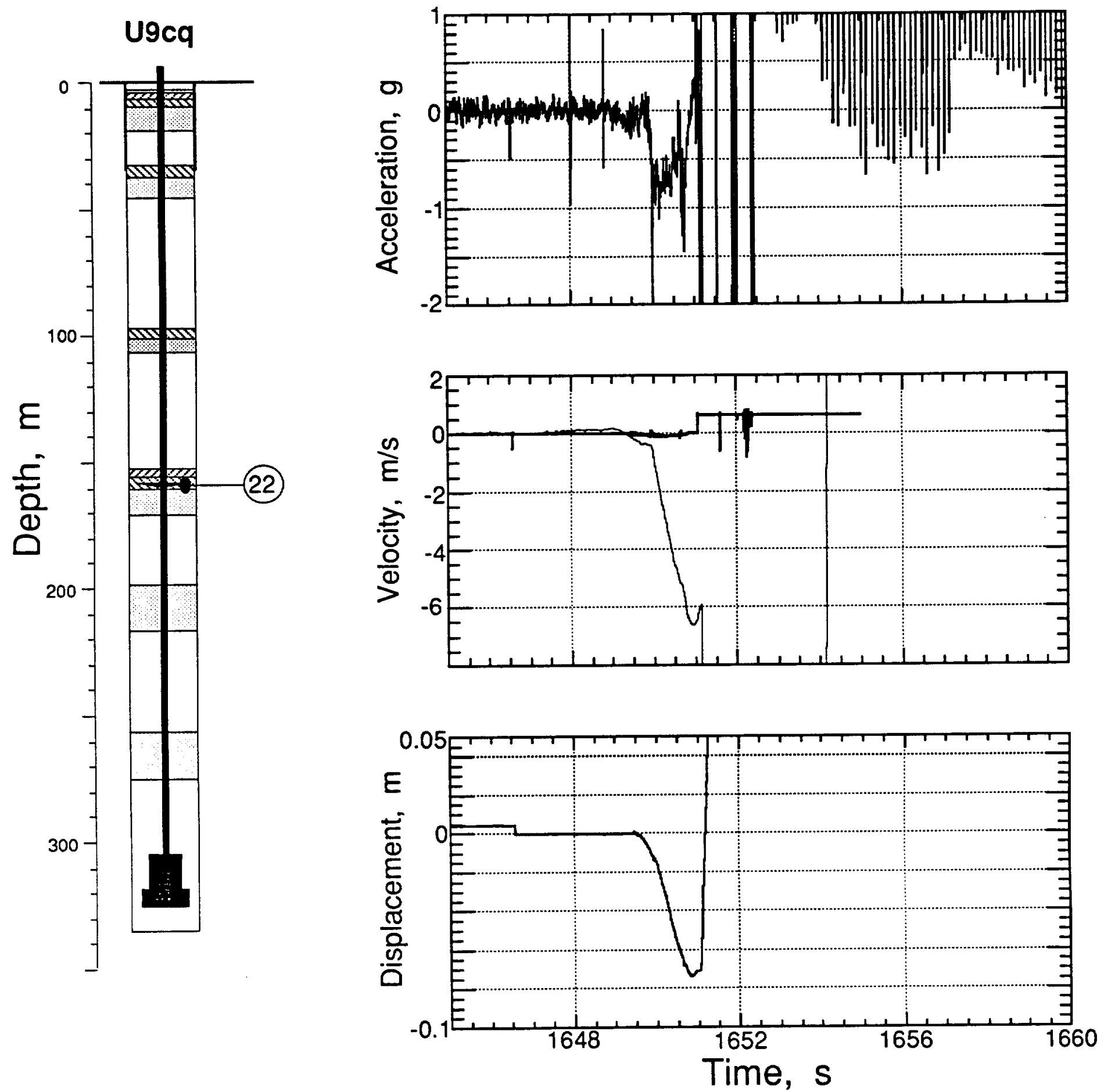

Figure 3.2 Collapse-induced vertical motion of the formation coupling plug (station 22, at a depth of $158.5 \mathrm{~m}$ ). When there are two traces in a single plot, the heavier is derived from the velocity transducer. The anomalous magnitude and wave form of the velocimeter trace strongly suggests that it be ignored. This plug was attached to the emplacement pipe by a drag ring. 

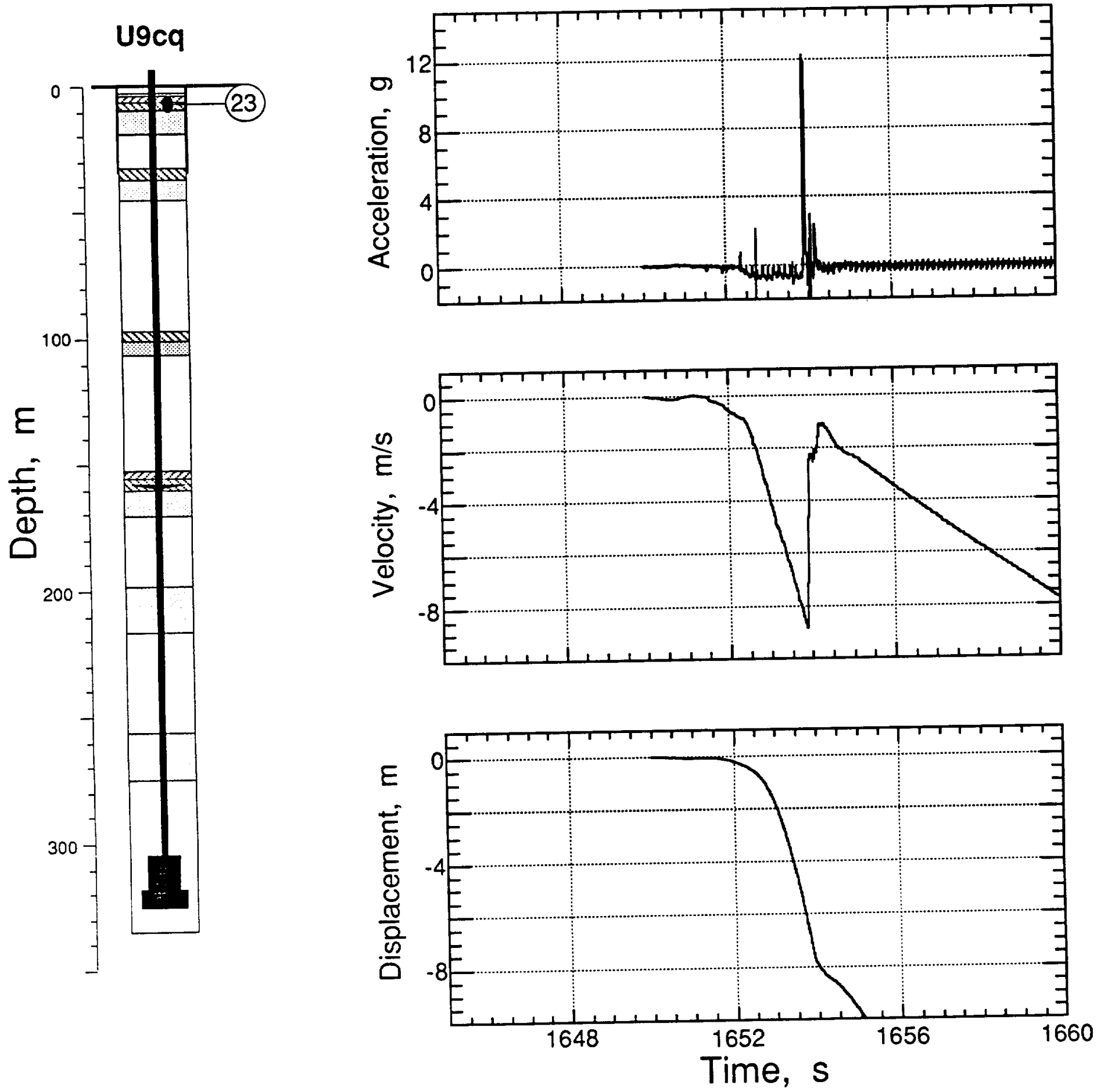

Figure 3.3 Collapse-induced vertical motion of the top rigid plug near the top of the surface casing (station 23 , at a depth of $7.6 \mathrm{~m}$ ). Only the accelerometer was operational at this station. 

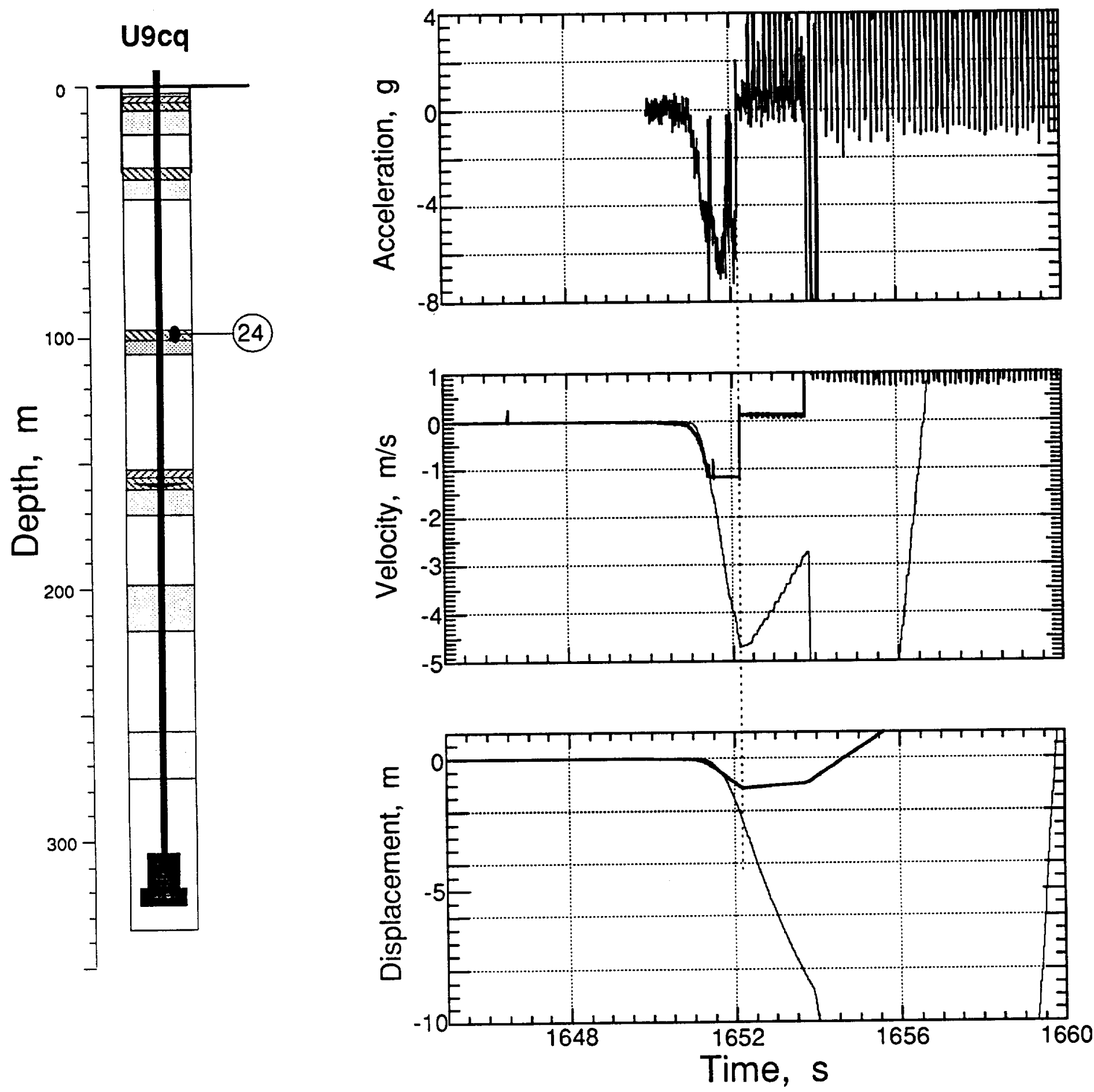

Figure 3.4 Collapse-induced vertical motion of the second rigid plug (station 24 at a depth of $38.5 \mathrm{~m}$ ). When there are two traces in a single plot, the heavier is derived from the velocity transducer. 

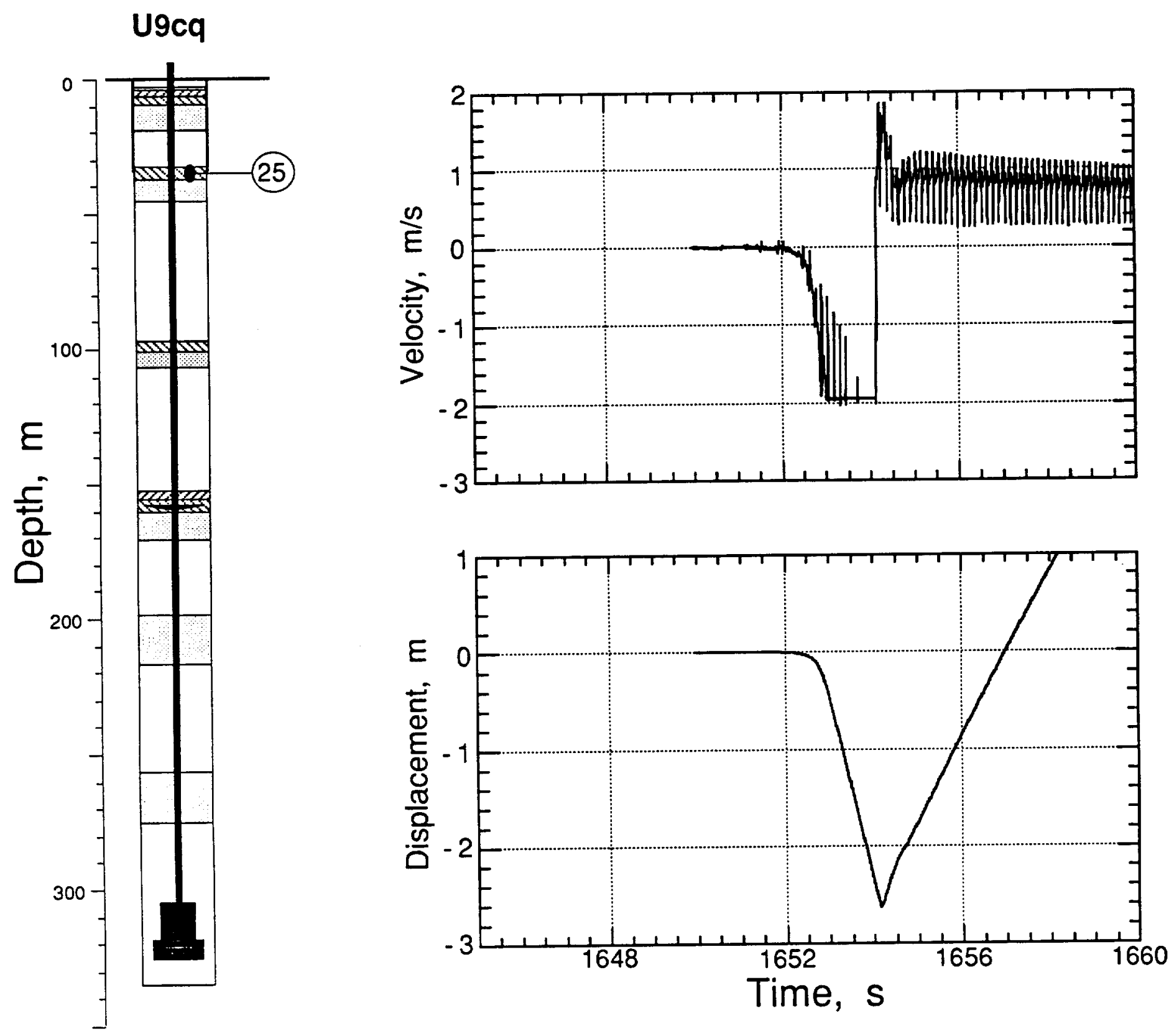

Figure 3.5 Collapse-induced vertical motion of the third rigid plug, extending part way into the surface casing (station 25, at a depth of $35.7 \mathrm{~m}$ ). The accelerometer at this location did not record. 

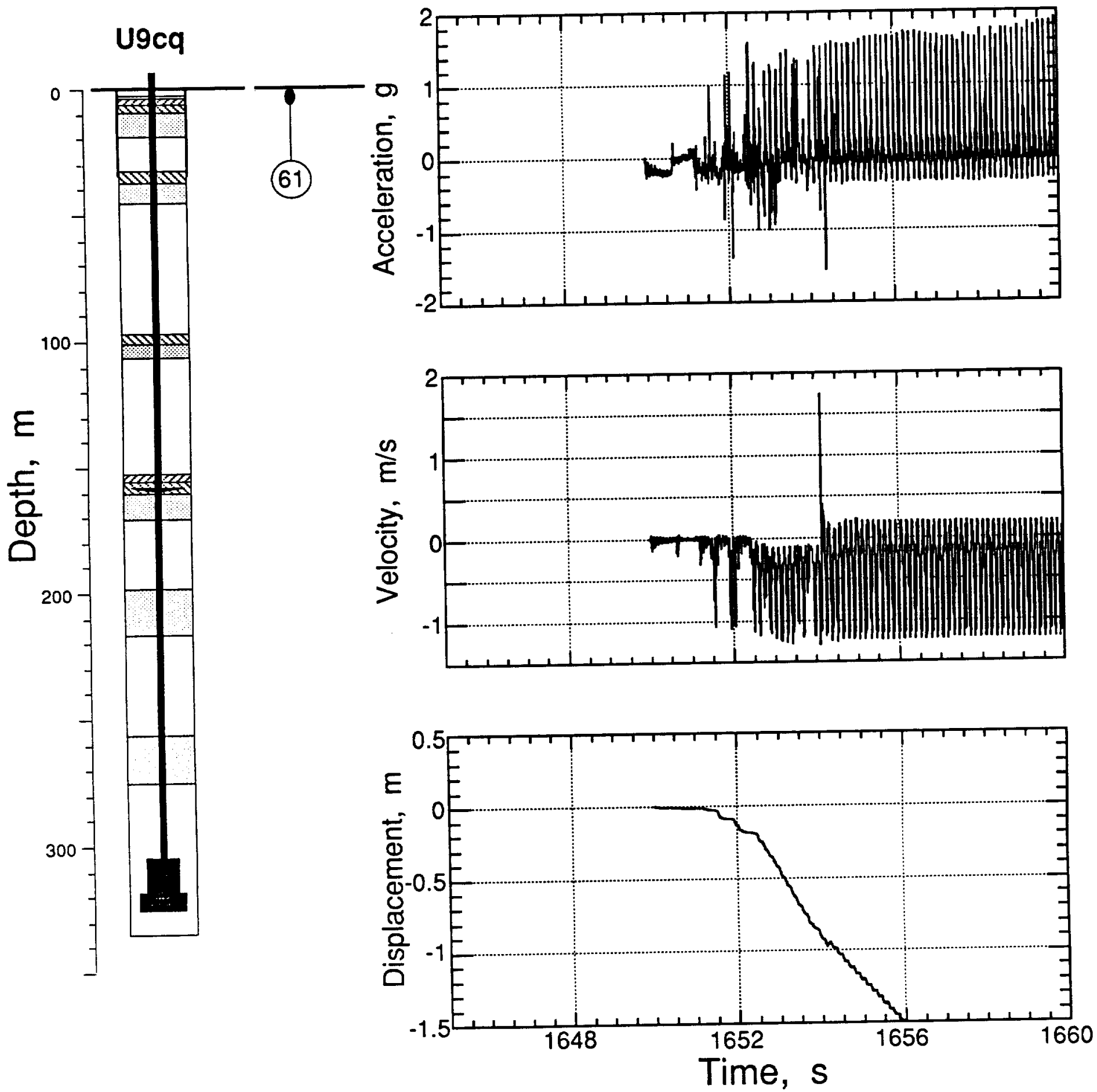

Figure 3.6 Collapse-induced vertical motion of the ground surface at a depth of $0.9 \mathrm{~m}$ and horizontal range of $15.24 \mathrm{~m}$ (station 61 ). 

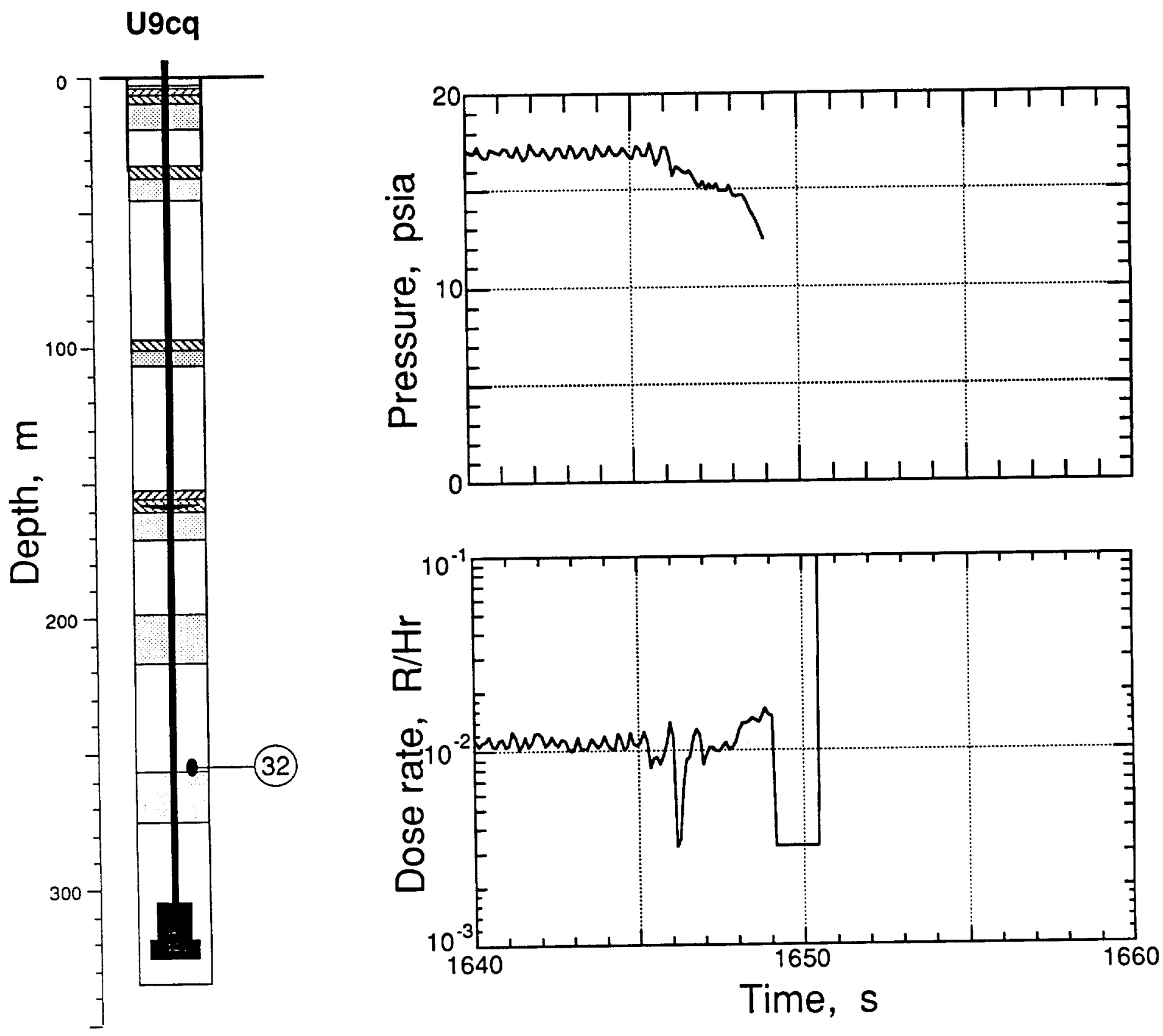

Figure 3.7 Collapse epoch pressure and radiation measured in the coarse stemming above the deep fines layer at a depth of $254.5 \mathrm{~m}$ (station 32). 

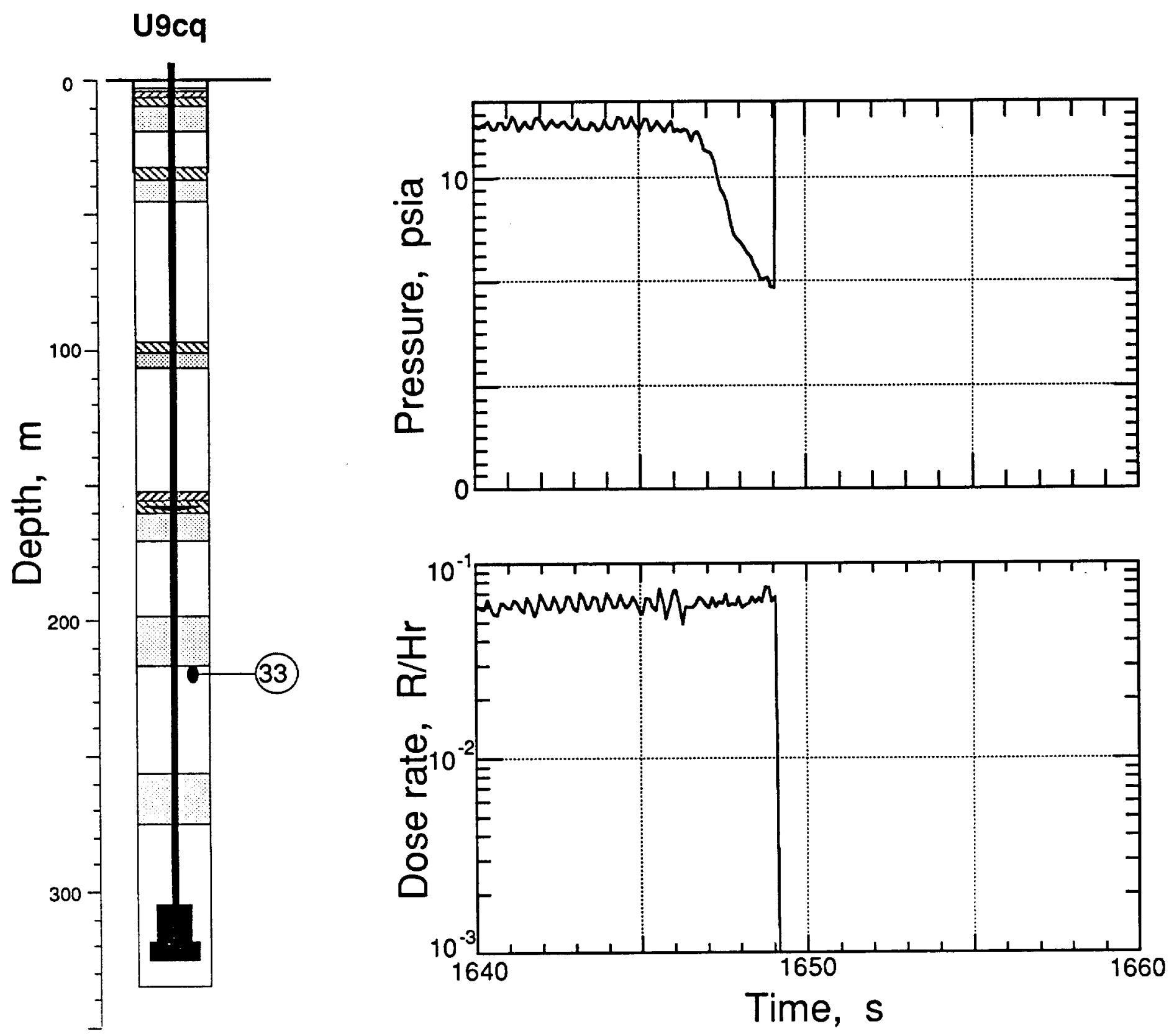

Figure 3.8 Collapse epoch pressure and radiation measured in the coarse stemming below the second fines layer at a depth of $219.5 \mathrm{~m}$ (station 33). 

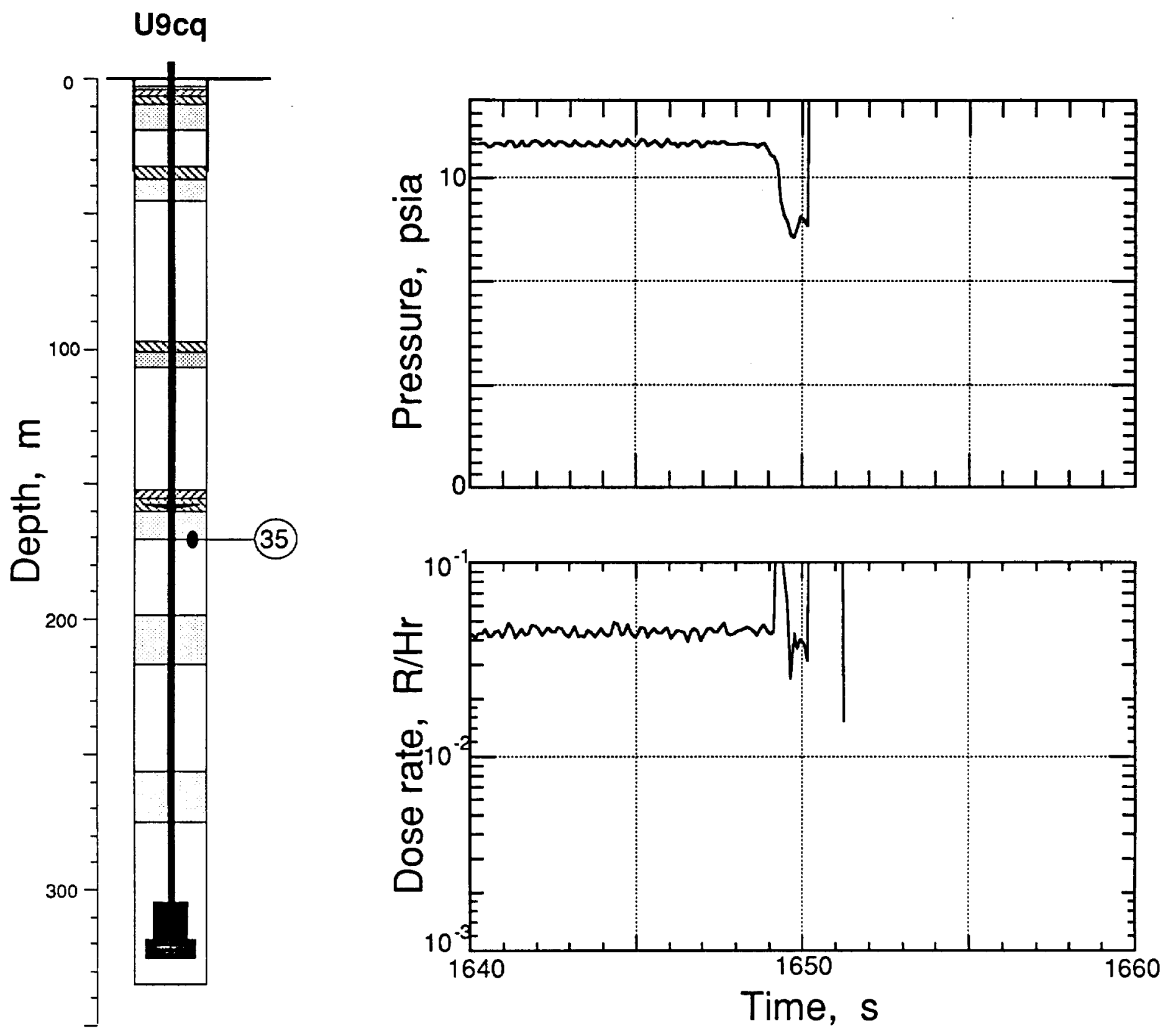

Figure 3.9 Collapse epoch pressure and radiation measured in the coarse stemming beneath the formation coupling plug at a depth of $170.7 \mathrm{~m}$ (station 35). 

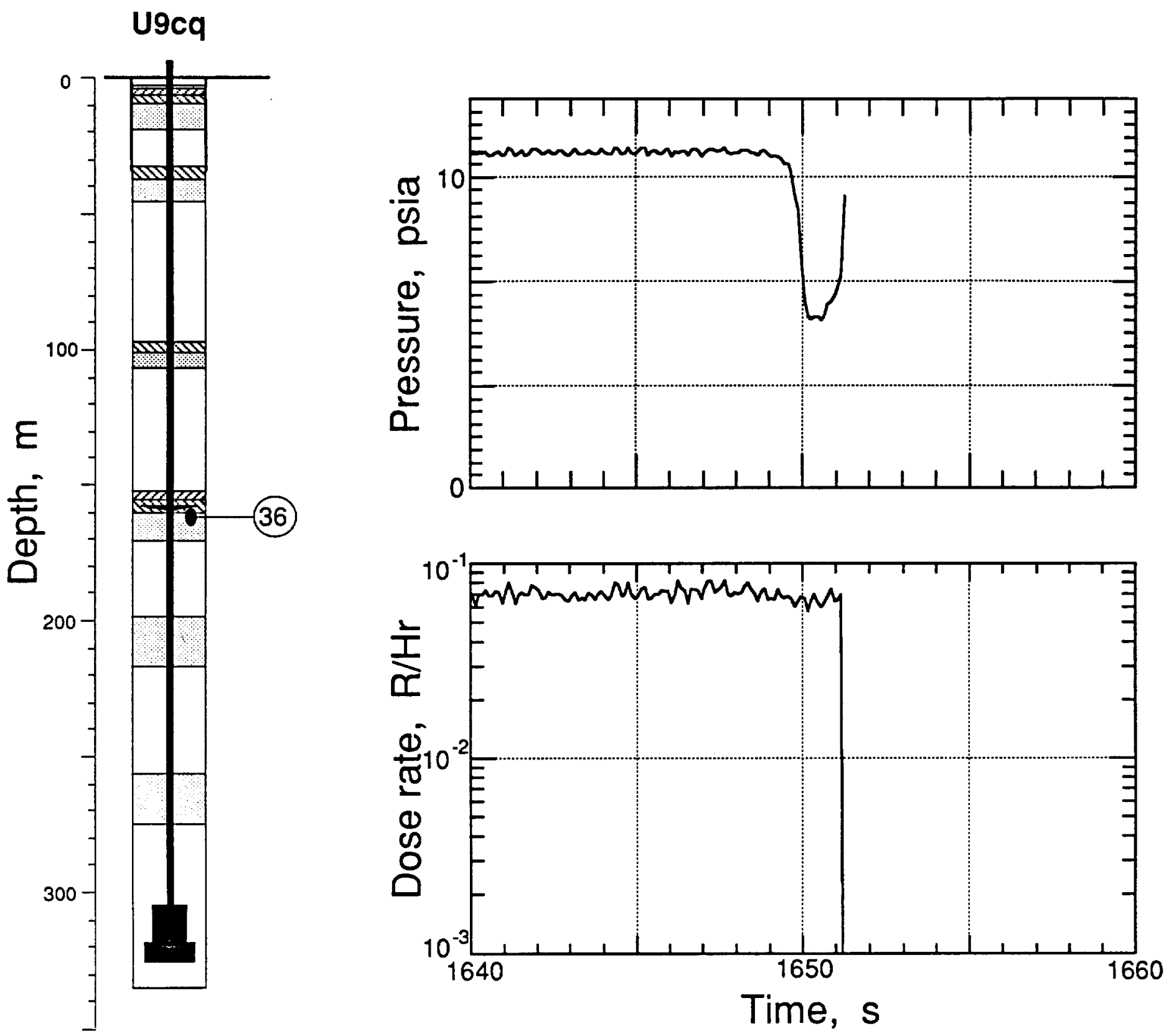

Figure 3.10 Collapse epoch pressure and radiation measured in the fines stemming beneath the formation coupling plug at a depth of $162.2 \mathrm{~m}$ (station 36 ). 

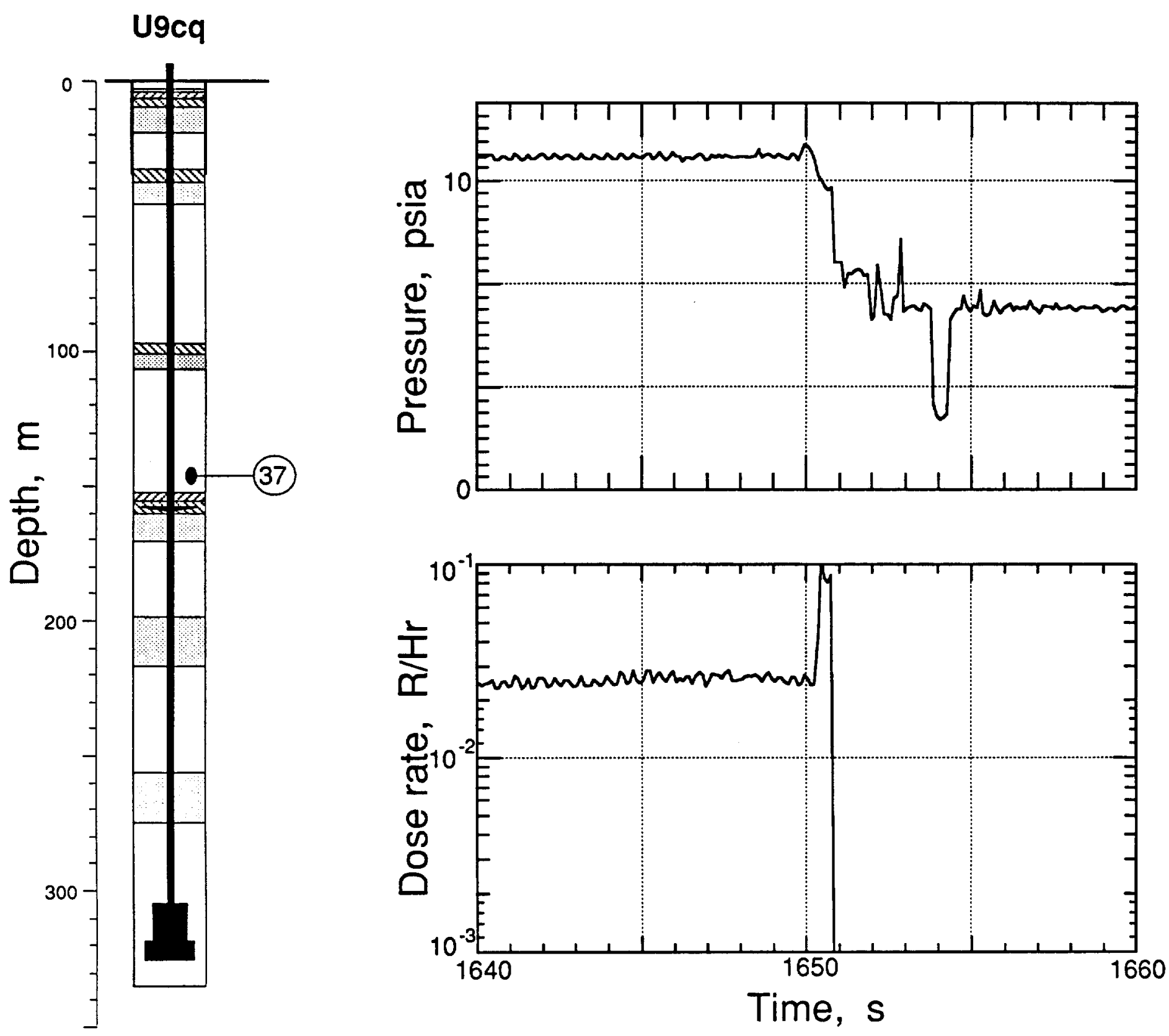

Figure 3.11 Collapse epoch pressure and radiation measured in the coarse stemming above the formation coupling plug at a depth of $146.3 \mathrm{~m}$ (station 37). 

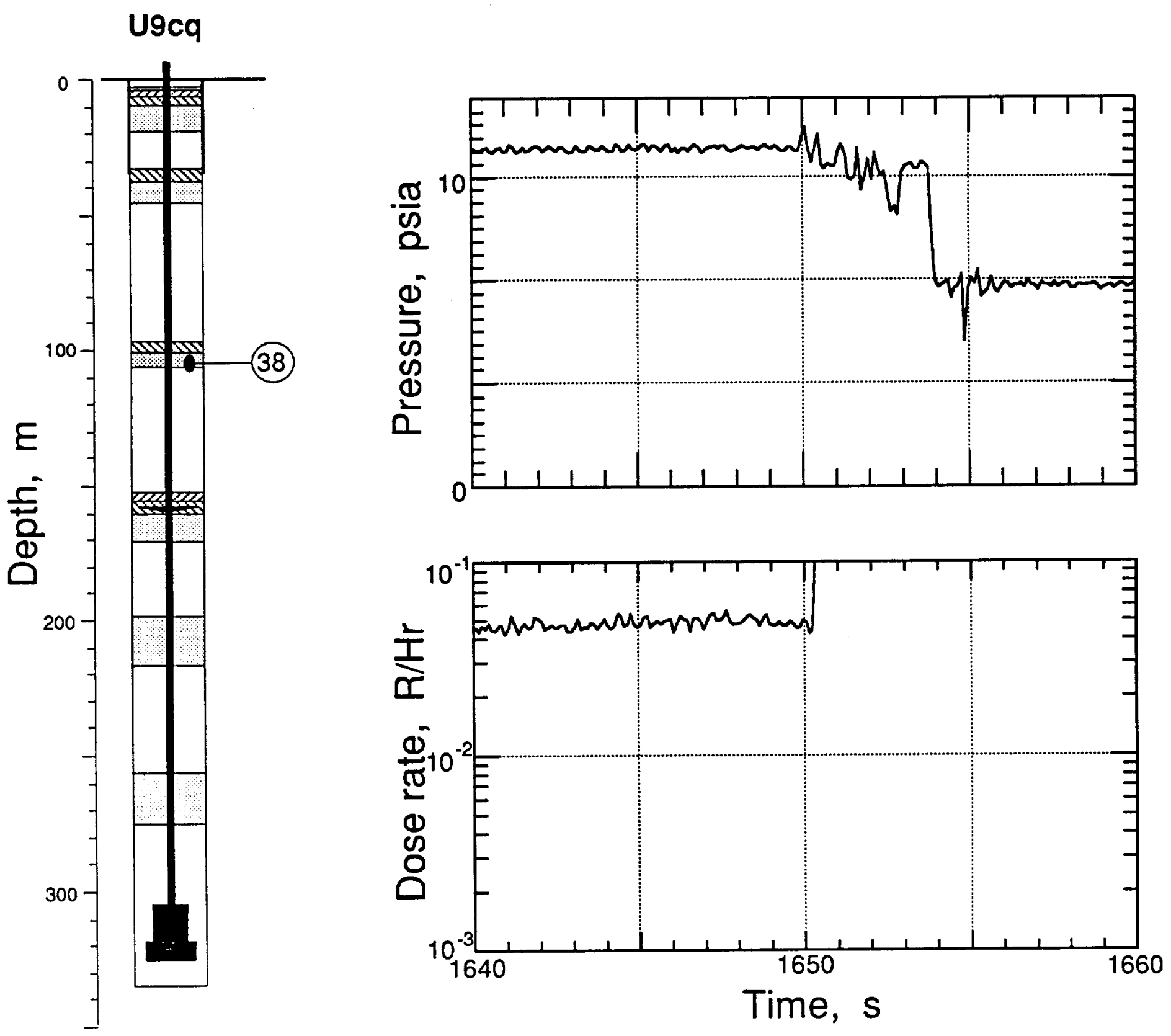

Figure 3.12 Collapse epoch pressure and radiation measured in the coarse stemming below the second rigid plug at a depth of $105.2 \mathrm{~m}$ (station 38). 

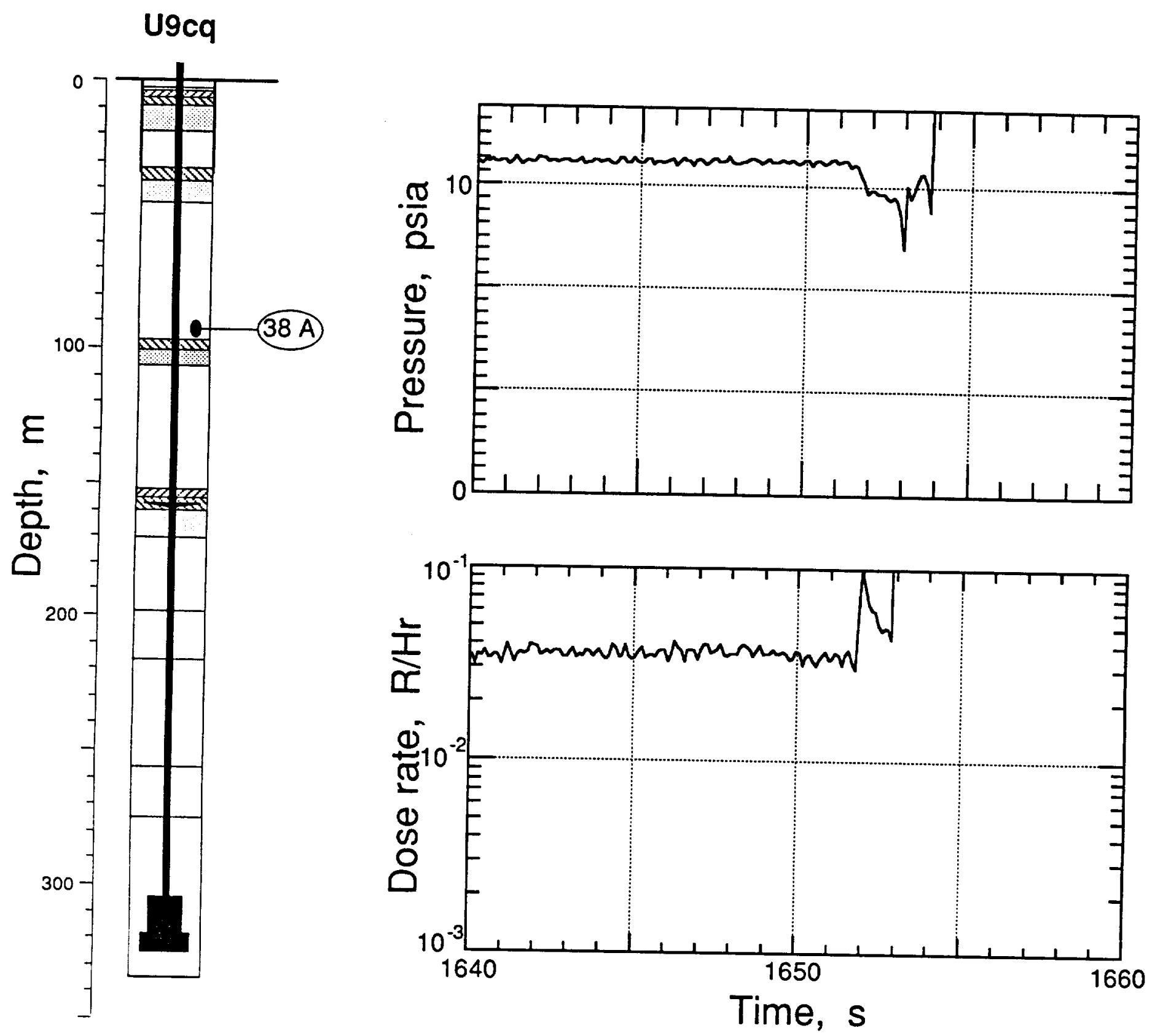

Figure 3.13 Collapse epoch pressure and radiation measured in the coarse stemming above the second rigid plug at a depth of $93.0 \mathrm{~m}$ (station 38A). 

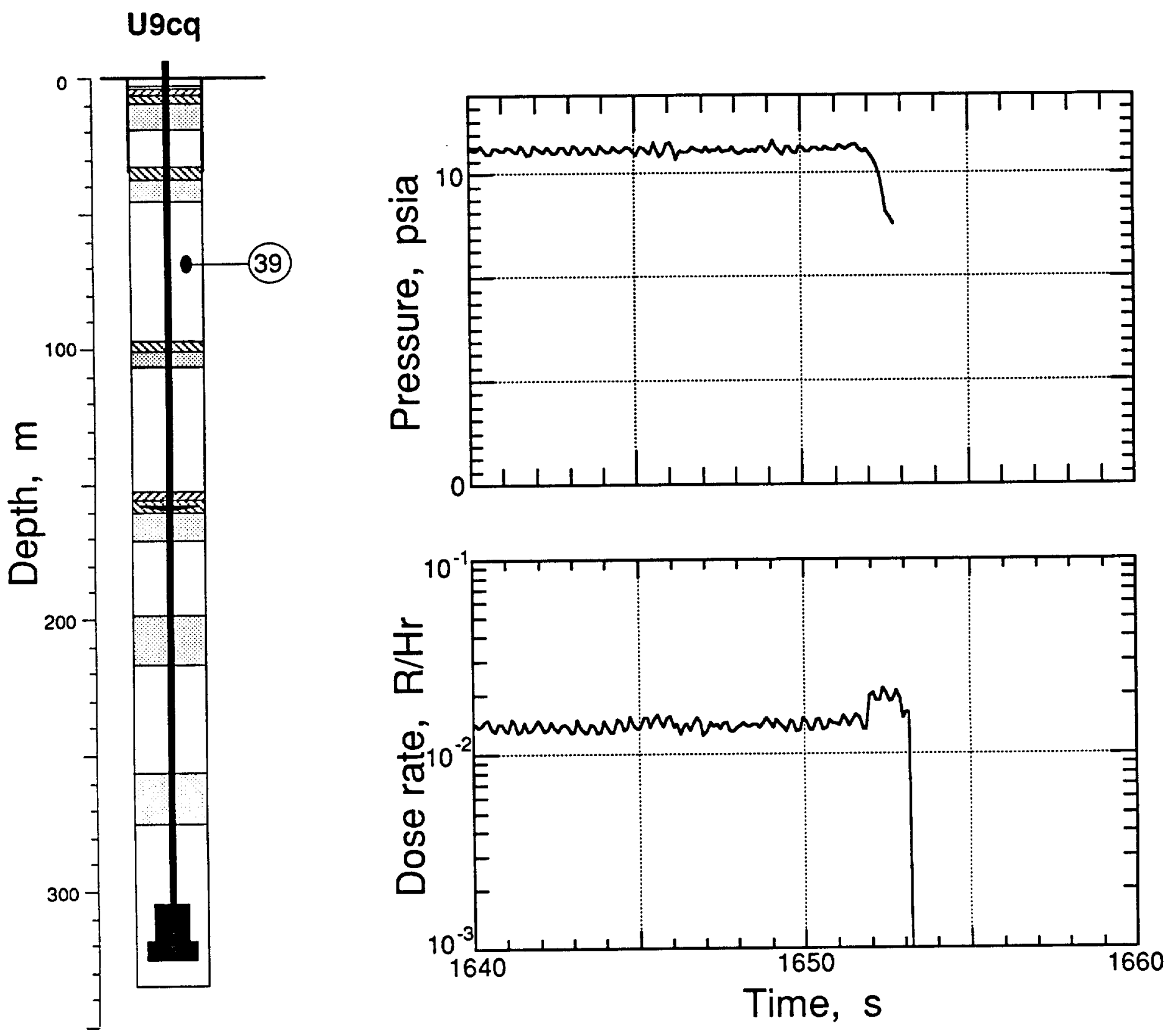

Figure 3.14 Collapse epoch pressure and radiation measured in the coarse stemming beneath the top plug at a depth of $68.6 \mathrm{~m}$ (station 39 ). 

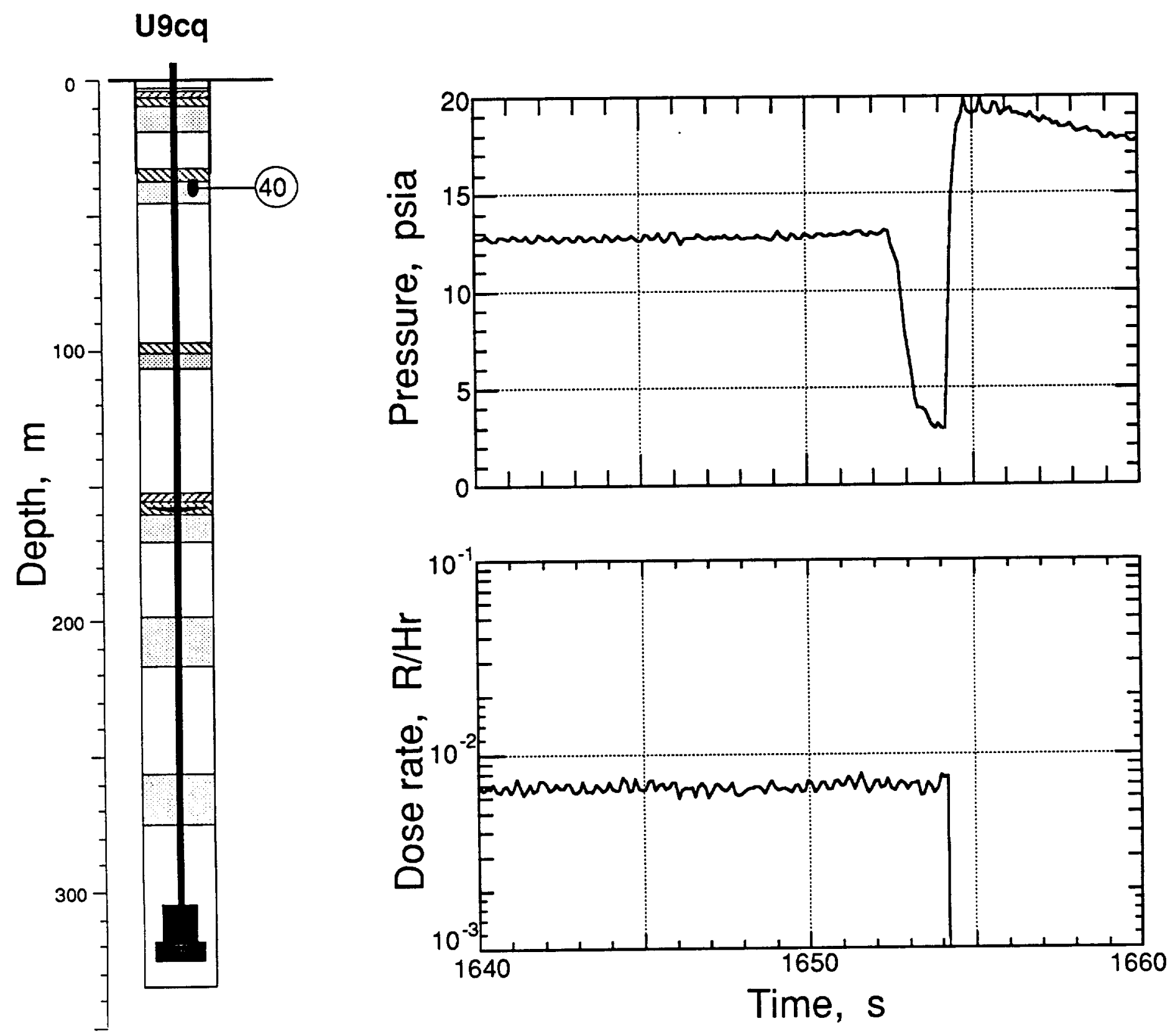

Figure 3.15 Collapse epoch pressure and radiation measured in the fines stemming beneath the top plug at a depth of $39.6 \mathrm{~m}$ (station 40 ). 


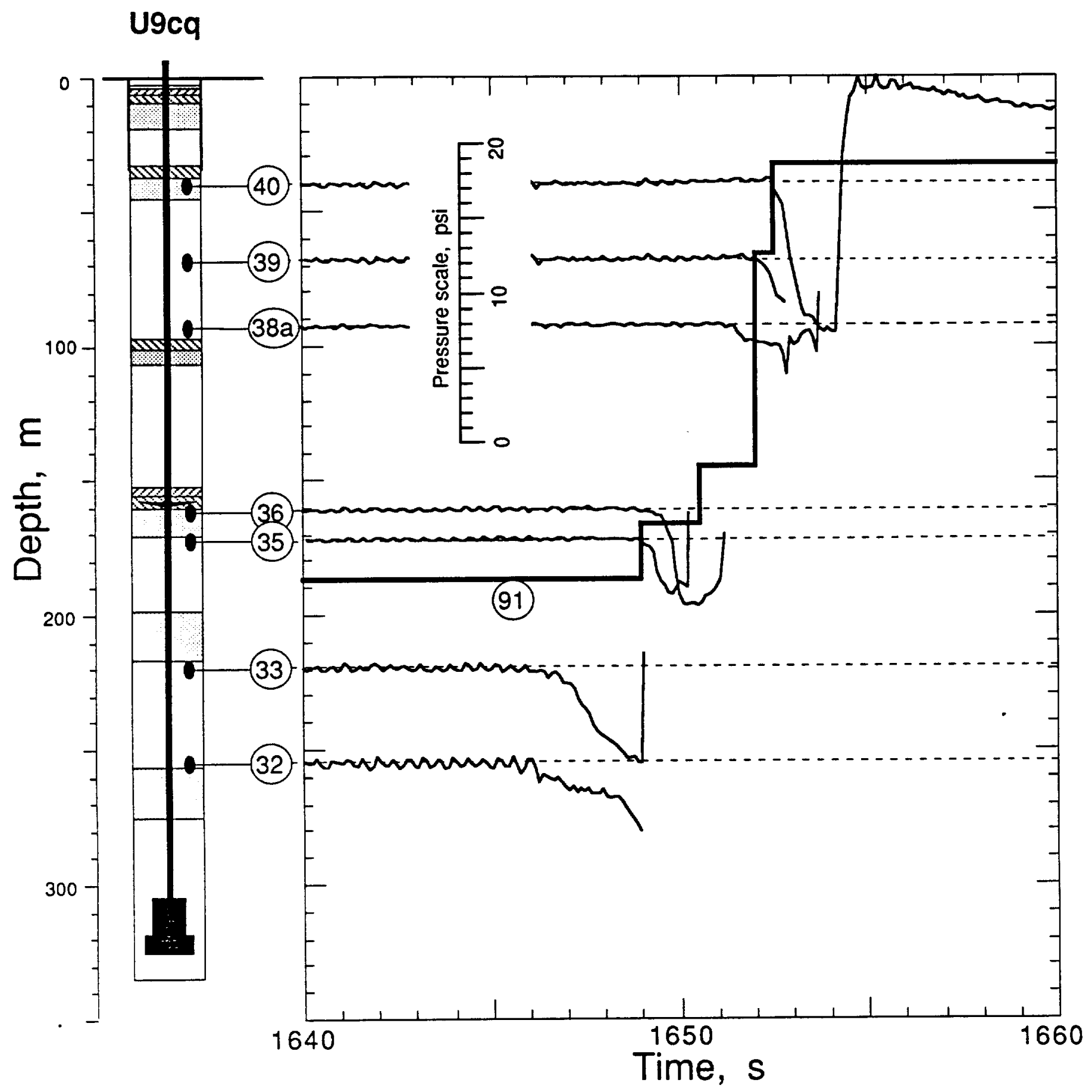

Figure 3.16 Progression of collapse as shown by the "open" elevation of the break in the D-cable (station 91). Also shown are representative pressure wave forms 


\section{Beferences}

1. Nancy W. Howard, "U9cq Preliminary Site Characteristics Summary", DM 81-10, Lawrence Livermore National Laboratory, Livermore, CA, January 19, 1981.

2. George Kronsbein, "Containment Report for U9cq," Holmes \& Narver, -62, July 7 , 1981.

3. W. G. Webb, "Special Measurements Final Engineering Report DAUPHIN, U9cq", EG\&G, Energy Measurements, Las Vegas, NV, SM:81E-87-33, 21 July 1981.

4. W. G. Webb, "Special Measurements Physics/Instrumentation Package for DAUPHIN, U9cq. Revision 'B' (final)", EG\&G, Energy Measurements, Las Vegas, NV, SM:81E-87-34, 21 July 1981. 
Distribution:

LLNL

TID/Brenda Staley (3)

Test Program Library

Containment Vault

Burkhard, N.

Cooper, $W$

Denny, $M$.

Goldwire, $H$.

Hannon, W. J.

Heinle, R. (5)

Mara, G.

Moran, M. T.

Moss, $W$.

Pawloski, G.

Rambo, J.

Valk, T.

LANL

Brunish, $W$.

Kunkle, $T$.

Trent, B.

Sandia

Bergstresser, $\mathbf{T}$.
BNLAVO

L-658

L-160

L-221

L-221

L-160

L-205

L-221

L-221

L-221

L-149

L-777

L-200

L-221

L-200

L-154

F-659

F.665

$F-664$

Brown, $T$.

A-5

Hatch, $M$.

A-5

Still, $G$.

Stubbs, T.

A-5

A-5

BNL/NVO

Bellow, B. $\quad$ N 13-20

Davies, L. N $\quad$ 13-20

Moeller, A. N 13-20

Robinson, R. N 13-20

Defense Special Weapons Agency

Ristvet, B.

Maxwell Technologies

Peterson, E.

Eastman Cherrington Environment

Keller, C.

MS-1159 


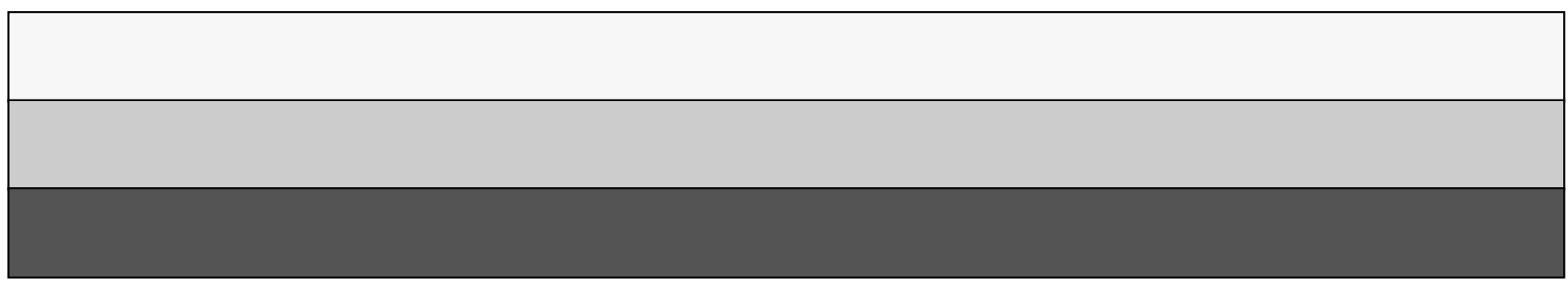

